\title{
A vertically resolved model for phytoplankton aggregation
}

\author{
IRIS KRIEST ${ }^{1}$ and GEOFFREY T EvANS ${ }^{2}$ \\ ${ }^{1}$ Institut für Meereskunde, Düsternbrooker Weg 20, 24105 Kiel, Germany. \\ ${ }^{2}$ Department of Fisheries and Oceans, P O Box 5667, St. John's, NF, Canada A1C 5X1.
}

This work presents models of the vertical distribution and flux of phytoplankton aggregates, including changes with time in the distribution of aggregate sizes and sinking speeds. The distribution of sizes is described by two parameters, the mass and number of aggregates, which greatly reduces the computational cost of the models. Simple experiments demonstrate the effects of aggregation on the timing and depth distribution of primary production and export. A more detailed ecological model is applied to sites in the Arabian Sea; it demonstrates that aggregation can be important for deep sedimentation even when its effect on surface concentrations is small, and it presents the difference in timing between settlement of aggregates and fecal pellets.

\section{Introduction}

The Arabian Sea exhibits large seasonal differences in the sedimentation of particulate organic matter (Haake et al 1993; Nair et al 1989). Especially in the western parts, deep flux is strongly coupled to the increase in wind speed during the Southwest Monsoon (SWM). This increase in deep sedimentation is accompanied by an increase in the proportion of biogenic silica, indicating a major contribution of diatoms to sedimentation. It has been proposed, that diatoms sink to these depths either via large (copepod) fecal pellets (Smith et al 1998), or in large, fast-settling aggregates, which are often observed during and after phytoplankton blooms in nearshore environments (Alldredge and Silver 1988; Alldredge and Gotschalk 1989) and in the open ocean, e.g. the North Atlantic (Lampitt 1985). Aggregates of Pseudonitzschia and Nitzschia closterium have also been observed in the the Arabian Sea (Garrison et al 1998).

Sedimentation of particulate organic matter (POM) is the product of mass and sinking speed of POM in the above layers. High concentrations of POM can be found, for example, as phytoplankton during blooms. The sinking speed of particles depends on various factors, such as the origin and size of particles. The sinking speed of phytoplankton may be enhanced when phytoplankton form large aggregates. Some large aggregates are formed by organisms, such as discarded mucus feeding webs, tunicate houses etc. (Alldredge and Silver 1988); others by the aggregation of smaller particles by purely physical processes. In the second type of aggregation, physical factors as turbulent shear or differences in the settling velocity of particles control the rate at which particles get into close proximity to each other. If the particles are sticky, they stay attached after contact, and form a larger particle.

Aggregation is a density dependent process, rapid during times of high phytoplankton abundance (Riebesell and Wolf-Gladrow 1992; Jackson 1990). It is therefore of interest to investigate the influence of (physical) phytoplankton aggregation and sedimentation together with the vertical transport of organic matter by fecal pellets in a biogeochemical model. Jackson (1990) and Riebesell and Wolf-Gladrow (1992) have created models of how the mechanisms of aggregation lead to changes in the size distribution of particles. These models describe the size distribution in great detail (hundreds of size classes) and are therefore too computationally demanding to be employed in large biogeochemical models with detailed spatial resolution.

Kriest (1999) and Kriest and Evans (1999; hereafter referred to as KE99) described a numerically efficient way to model the size distribution of particles and how it changes over time. We presented results for a

Keywords. Model; phytoplankton; aggregation; Arabian Sea. 
well-mixed surface layer. In the present paper we shall study also the coupling between surface events and what reaches the deep ocean - for example what is recorded in sediment traps almost a kilometre below the production events that create the original small particles. In this paper we study the representation of KE99 in a model in which the water column is resolved into many numerical layers. We consider first the range of behaviour possible in even the simplest biogeochemical model that represents the necessary processes of particle formation and aggregation. We then describe a more ecological model including zooplankton, and their fecal pellets as another type of sinking particle, and compare its results with data collected in the Arabian Sea.

\section{The nutrient-phytoplankton model}

\subsection{Simulations with constant physical forcing}

\subsubsection{Model structure}

Mass balances. We model nutrient and phytoplankton concentrations in a water column in which all components undergo vertical mixing, and phytoplankton sink. Phytoplankton growth is limited by the product of nutrient and light terms. The equations for nitrate (NO3) and phytoplankton mass (PHY) and numbers (PHYNOS) are:

$$
\begin{aligned}
\frac{\partial \mathrm{NO} 3}{\partial t}= & -\frac{\mathrm{NO} 3}{k_{\mathrm{NO} 3}+\mathrm{NO} 3} J(z, t) \mathrm{PHY} \\
& +\frac{\partial}{\partial z} K(z) \frac{\partial \mathrm{NO} 3}{\partial z}, \\
\frac{\partial \mathrm{PHY}}{\partial t}= & \frac{\mathrm{NO} 3}{k_{\mathrm{NO} 3}+\mathrm{NO} 3} J(z, t) \mathrm{PHY} \\
& +\frac{\partial}{\partial z} K(z) \frac{\partial \mathrm{PHY}}{\partial z}-\frac{\partial \Psi}{\partial z}, \\
\frac{\partial \mathrm{PHYNOS}}{\partial t}= & \frac{\mathrm{NO} 3}{k_{\mathrm{NO} 3}+\mathrm{NO} 3} J(z, t) \mathrm{PHYNOS} \\
& +\frac{\partial}{\partial z} K(z) \frac{\partial \mathrm{PHYNOS}}{\partial z}-\frac{\partial \Phi}{\partial z}-\xi
\end{aligned}
$$

where $J(z, t)$ describes light limitation, $\Psi$ is the vertical flux of phytoplankton mass, $\Phi$ the flux of numbers of particles, and $\xi$ the rate of aggregation of particles. Cell growth and division is assumed to produce more aggregates, not larger aggregates: cells separate after they divide. We now describe the flux and aggregation terms in detail.

Representation of phytoplankton aggregates. As in KE99 we assume that the distribution of aggregates as a function of diameter can be described by a twoparameter function $p(\theta)=A \theta^{-\epsilon}$ over a size range from $m$, the diameter of a (typical) single cell, to $\infty$. The total number of phytoplankton aggregates PHYNOS is thus

$$
\begin{aligned}
\text { PHYNOS }= & A \int_{m}^{\infty} \theta^{-\epsilon} \mathrm{d} \theta=A \frac{m^{1-\epsilon}}{\epsilon-1} \\
& \text { provided } \epsilon>1 .
\end{aligned}
$$

If the mass, $C$, of an aggregate is related to its diameter, $\theta$, by $C(\theta)=C \theta^{\zeta}$, and $C_{m}=C m^{\zeta}$ is the mass of a single cell, then the total mass of phytoplankton aggregates is

$$
\begin{aligned}
\mathrm{PHY}= & A C \int_{m}^{\infty} \theta^{\zeta-\epsilon} \mathrm{d} \theta=A C_{m} \frac{m^{1+\zeta-\epsilon}}{\epsilon-1-\zeta} \\
& \text { provided } \quad \epsilon>\zeta+1 .
\end{aligned}
$$

Equations (4) and (5) can be solved for $A$ and $\epsilon$ in terms of PHY and PHYNOS; so, the shape of the size distribution is a dynamical variable.

Sinking. The sinking flux of numbers and mass of phytoplankton aggregates are given by

$$
\begin{aligned}
& \Phi(z)=\int_{m}^{\infty} p(z, \theta) w(\theta) \mathrm{d} \theta \text { and } \\
& \Psi(z)=C \int_{m}^{\infty} p(z, \theta) \theta^{\zeta} w(\theta) \mathrm{d} \theta
\end{aligned}
$$

where $w(\theta)$ is the sinking speed of a particle of size $\theta$. Because the size distribution exponent varies with depth and time, average sinking speeds also vary with depth and time. KE99 assumed $w=B \theta^{\eta}$. All the indefinite integrals (from $m$ to $\infty$ ) must converge. In the model for a single well-mixed layer, the largest particles sink out. Thus, provided the initial model conditions are set up so that the integrals converge, no subsequent divergences can evolve. In a vertically resolved model there is an extra complication: the largest particles that sink out of one layer sink into the layer below and shift its size distribution towards larger cells. This effect cannot trigger a divergent integral of mass, of course; but it can trigger a divergence of average sinking speed. To sidestep this problem, we arbitrarily decide that the increase of sinking speed with particle mass has an upper limit at mass $M: w=B \min (\theta, M)^{\eta}$. The effect of this upper limit is negligible in practice: it is the difference between sinking at $1900 \mathrm{~m} /$ day, which is fast enough to leave no influence on the water column, and infinitely fast.

Aggregation. The probability of collision of particles is a function of particle size, concentration, the rate of turbulent shear and the difference of the settling velocities of two different particles. The equations for collisions due to shear and differential settlement as presented by Jackson (1990) have been converted to a size-continuous form and solved. To bound the aggregation integrals from getting out of the range of 
convergence, we assume that for particles larger than $M$ the probability of colliding no longer depends on particle size. The integrals are evaluated in Appendix A.1 and A.2. Their sum times the probability that two particles stick together after contact then gives the rate of aggregation.

\subsubsection{Model setup}

We run the model for a water column of $400 \mathrm{~m}$ depth. The grid of Haupt (1995) is used to give extra resolution near the surface where light gradients are strongest. The layer thicknesses $(\Delta z(n))$ are given by:

$$
\begin{gathered}
\Delta z(1)=1 \mathrm{~m} \text { and } \Delta z(n)=e^{n / 12} \Delta z(1) \text { for } \\
n=2,42 .
\end{gathered}
$$

The first 21 boxes are situated in the upper $60 \mathrm{~m}$, where the depth resolution ranges from $1 \mathrm{~m}$ for the uppermost box to $5.75 \mathrm{~m}$. The deepest box has a thickness of $33 \mathrm{~m}$. There is a constant mixed layer depth of $25 \mathrm{~m}$. The turbulent eddy diffusion coefficient is set to $K_{u p}=200 \mathrm{~cm}^{2} \mathrm{~s}^{-1}$ above the thermocline, and to $K_{\text {low }}=0.125 \mathrm{~cm}^{2} \mathrm{~s}^{-1}$ below the thermocline.

Because mixing and ecological interactions can have very different time scales, the model equations are solved using the method of lines and an implicit ordinary differential equation solver (VODE; Brown et al 1989).

Light limitation $J(z, t)$ for a grid box is averaged over the box thickness and integrated over one day as in Evans and Parslow (1985), using the rational function approximation of Evans and Garçon (1997). Light for a given depth $z$ is calculated by

$$
I(z, t)=I_{0}(t) e^{\int_{0}^{z}\left(k_{w}+k_{c} \mathrm{PHY}\right) d z}
$$

where the surface light $I_{0}(t)$ varies seasonally, and $k_{w}$ and $k_{c}$ are the attenuation coefficients for water and phytoplankton, respectively. The attenuation coefficient for phytoplankton is independent of its aggregation state.

Parameters. Phytoplankton maximum growth rate $\mu_{\mathrm{PHY}}$ has been set to a value of $2.5 \mathrm{~d}^{-1}$. The parameters for the influence of light on phytoplankton growth have been chosen mainly in accordance with Fasham et al (1990; see table 1). Using these parameters and surface solar radiation as appropriate for e.g. $10^{\circ} \mathrm{N}$ on January $1\left(\approx 141 \mathrm{~W} \mathrm{~m}^{-2}\right)$ the phytoplankton growth rate in the first layer is always around $1 \mathrm{~d}^{-1}$, about the same as in KE99. In deeper layers, of course phytoplankton growth is reduced due to lower light. The half-saturation constant $k_{\mathrm{NO} 3}$ for nitrate uptake by phytoplankton has been set to such a low value that almost all of the nitrate in the upper layers will be used by phytoplankton. As turbulent kinetic energy below the mixed layer is usually low, shear below the mixed layer has been set to zero, i.e. below the mixed layer aggregation only takes part due to differential settlement. The upper boundary, $M$, for

\begin{tabular}{|c|c|c|c|c|}
\hline Parameter & Symbol & CONST & AS & Unit \\
\hline $\begin{array}{l}\text { Phytoplankton parameters } \\
\text { Maximum growth rate } \\
\text { Half-sat. const. } \\
\text { PHY-specific atten. coeff. } \\
\text { Water atten. coeff. } \\
\text { Initial slope of P-I curve } \\
\text { Mortality }\end{array}$ & $\begin{array}{c}\mu_{\mathrm{PHY}} \\
k_{\mathrm{NO} 3} \\
k_{c} \\
k_{w} \\
\alpha \\
\lambda_{\mathrm{PHY}}\end{array}$ & $\begin{array}{c}2.5 \\
0.05 \\
0.03 \\
0.04 \\
0.025 \\
0\end{array}$ & $\begin{array}{c}2.5 \\
0.50 \\
0.03 \\
0.04 \\
0.025 \\
0.04\end{array}$ & $\begin{array}{l}\mathrm{d}^{-1} \\
\mathrm{mmolN} \mathrm{m} \mathrm{m}^{-3} \\
\mathrm{mmolN}^{-1} \mathrm{~m}^{2} \\
\mathrm{~m}^{-1} \\
\left(\mathrm{~d} \mathrm{~W} \mathrm{~m} \mathrm{~m}^{-2}\right)^{-1} \\
\mathrm{~d}^{-1}\end{array}$ \\
\hline $\begin{array}{l}\text { Zooplankton parameters } \\
\text { Maximum growth rate } \\
\text { Half-sat. const. for grazing } \\
\text { Assimilation efficiency } \\
\text { Excretion rate } \\
\text { Mortality rate }\end{array}$ & $\begin{array}{l}\mu_{\mathrm{ZOO}} \\
k_{\mathrm{PHY}} \\
\epsilon_{\mathrm{ZOO}} \\
\lambda_{\mathrm{ZOO}} \\
\kappa_{\mathrm{ZOO}}\end{array}$ & $\begin{array}{l}- \\
- \\
- \\
-\end{array}$ & $\begin{array}{c}1.0 \\
1.0 \\
0.75 \\
0.1 \\
0.05\end{array}$ & $\begin{array}{l}\mathrm{d}^{-1} \\
\mathrm{mmol} \mathrm{N} \mathrm{m}^{-3} \\
\mathrm{~d}^{-1} \\
\mathrm{~d}^{-1} \mathrm{mmol} \mathrm{N} \mathrm{m}^{-3}\end{array}$ \\
\hline $\begin{array}{l}\text { Detritus parameters } \\
\text { Decay rate } \\
\text { Sinking speed }\end{array}$ & $\begin{array}{l}\lambda_{\mathrm{DET}} \\
w_{\mathrm{DET}}\end{array}$ & - & $\begin{array}{l}0.04 \\
10.0\end{array}$ & $\begin{array}{l}\mathrm{d}^{-1} \\
\mathrm{md}^{-1}\end{array}$ \\
\hline $\begin{array}{l}\text { Aggregation parameters } \\
\text { Shear rate } \\
\text { Sinking exponent } \\
\text { Sinking factor } \\
\text { Stickiness } \\
\text { Cell size } \\
\text { N content exponent } \\
\text { N content coefficient }\end{array}$ & $\begin{array}{l}\text { shear } \\
\quad \eta \\
B \\
\text { stick } \\
m \\
\zeta \\
C\end{array}$ & $\begin{array}{c}0.84 \\
1.17 \\
1.10 \\
0.1 \\
0.002 \\
2.28 \\
5.67\end{array}$ & $\begin{array}{c}0.84 \\
1.17 \\
1.10 \\
0.1 / 0.5 \\
0.002 \\
2.28 \\
5.67\end{array}$ & $\begin{array}{l}\mathrm{s}^{-1} \\
- \\
\mathrm{cm}^{-0.17} \mathrm{~s}^{-1} \\
- \\
\mathrm{cm} \\
- \\
\mathrm{nmol} \mathrm{N} \mathrm{cm}\end{array}$ \\
\hline
\end{tabular}
the evaluation of the sinking and aggregation

Table 1. Parameters for model simulations with constant physical forcing (CONST) and in the Arabian Sea (AS). 
equations in all following simulations has been set to a rather high value of $M=2 \mathrm{~cm}$. This is about the maximum size for which investigations related to the diameter - sinking relationship exist (Alldredge and Gotschalk 1988).

Four simulations have been performed with the model:

- a base run with the parameters as shown in table 1 and uniform initial nitrate and phytoplankton profiles of 10 and $0.001 \mathrm{mmol} \mathrm{N} \mathrm{m}^{-3}$, respectively;

- the stickiness is increased by a factor of five to increase the influence of aggregation (see table 2);

- in addition to increased stickiness, the nitrate profile concentration is decreased to half of the value of the base run;

- the aggregation is stopped by setting the stickiness to zero. In this last scenario, all phytoplankton sink at the low, constant sinking speed of a single cell $\left(0.7 \mathrm{~m} \mathrm{~d}^{-1}\right)$.

\subsubsection{Results}

Figure 1 shows phytoplankton mass (contour lines) and the time and depth where the mass of aggregates that sink at least 10 or $100 \mathrm{~m} \mathrm{~d}^{-1}$ (corresponding to an aggregate size of ca. 0.2 and $1.5 \mathrm{~mm}$, respectively) is greater than $0.01 \mathrm{mmol} \mathrm{N} \mathrm{m}^{-3}$ (light and dark grey area, respectively) for the base run and the three experiments over a time period of 90 days with a constant physical forcing.

Starting from low phytoplankton concentrations $\left(0.001 \mathrm{mmol} \mathrm{N} \mathrm{m}^{-3}\right)$, a steep size distribution $(\epsilon=8$; average size $\approx 1.5$ cells per aggregate) and a high nitrate concentration of $10 \mathrm{mmol} \mathrm{N} \mathrm{m}^{-3}$, phytoplankton in the well-lit mixed layer increases to a maximum value of almost $9 \mathrm{mmol} \mathrm{N} \mathrm{m}^{-3}$, as all of the nitrate there is taken up. Phytoplankton is distributed homogeneously throughout the mixed layer, and decreases below due to shading. At the end of the surface bloom, large aggregates start to form especially in the mixed layer, where shear is high and facilitates aggregation. The large aggregates sink to deeper layers, and leave behind the smaller particles, which settle at lower rates.

Following day 20, the large aggregates have settled out of the mixed layer and there are no longer sufficient particle concentrations in the euphotic zone to fuel aggregation. Phytoplankton mixed layer concentration has decreased to less than $1 \mathrm{mmol} \mathrm{N} \mathrm{m}^{-3}$ on day 50. Following the mixed layer bloom, a deep phytoplankton maximum is established at a depth where nitrate is still high, and light is still sufficient to promote phytoplankton growth. The phytoplankton maximum corresponds to a Deep Chlorophyll Maximum (DCM), that is commonly observed in nature, e.g. during the intermonsoon season in the western Arabian Sea (see Banse 1994, for a discussion about the occurrence and persistence of a DCM in the Arabian Sea). The DCM in the model would be even higher if there was shade adaptation, i.e. if a varying Chl:N ratio was modelled, that depends on the light regime the phytoplankton is exposed to.

Figure 2 shows the logarithm of the rate of aggregation (rate of collisions times stickiness) for collisions due to shear in the mixed layer (upper panel of figure 2) and the vertically resolved plot of collisions due to differential settlement for the base run.

Collisions due to shear in the mixed layer are about one order of magnitude higher rate than collisions due to differential settlement. This fact can be explained by the structure of the kernels of the corresponding equations, which have been discussed in more detail in Kriest (1999). The rate of turbulent shear for layers below the mixed layer in this model has been set to zero, so there are no collisions due to shear below the mixed layer, and differential settlement is the only mechanism that produces large aggregates. Because the DCM is situated below the mixed layer, it settles only slowly to deeper layers during the course of the simulation.

Table 2. Maximum phytoplankton concentration, primary production (integrated over depth and time), sedimentation in 25 and $400 \mathrm{~m}$ integated over simulation time (tF25 and tF400) and over the first 20 days of simulation (eF25 and eF400) for model experiments. Additionally, sedimentation in $400 \mathrm{~m}$ is given as percentage of the sedimentation in $25 \mathrm{~m}$

\begin{tabular}{|c|c|c|c|c|}
\hline Scenario & Base & Sticky & Sticky/Low NO3 & No Aggregation \\
\hline \multicolumn{5}{|l|}{ Parameter: } \\
\hline Stickiness & 0.1 & 0.5 & 0.5 & 0 \\
\hline Initial NO3 $\left(\mathrm{mmol} \mathrm{N} \mathrm{m}^{-3}\right)$ & 10 & 10 & 5 & 10 \\
\hline Sinking speed $\left(\mathrm{m} \mathrm{d}^{-1}\right)$ & variable & variable & variable & 0.7 \\
\hline \multicolumn{5}{|l|}{ Diagnostic: } \\
\hline Max. PHY $\left(\operatorname{mmol~} \mathrm{Nm}^{-3}\right)$ & 8.94 & 7.11 & 5.00 & 9.33 \\
\hline $\mathrm{PP}\left(\mathrm{mmol} \mathrm{N} \mathrm{m}{ }^{-2}\right)$ & 617 & 704 & 410 & 426 \\
\hline $\mathrm{tF} 25\left(\mathrm{mmol} \mathrm{N} \mathrm{m}^{-2}\right)$ & 313 & 302 & 149 & 280 \\
\hline $\mathrm{eF} 25(\%$ of $\mathrm{tF} 25)$ & 42 & 84 & 78 & 20 \\
\hline tF400 $\left(\mathrm{mmol} \mathrm{N} \mathrm{m}^{-2}\right)$ & 227 & 366 & 186 & 0 \\
\hline eF400 (\% of tF400) & 16 & 59 & 49 & 0 \\
\hline $\mathrm{tF} 400 / \mathrm{tF} 25(\%)$ & 73 & 121 & 125 & 0 \\
\hline
\end{tabular}


Base

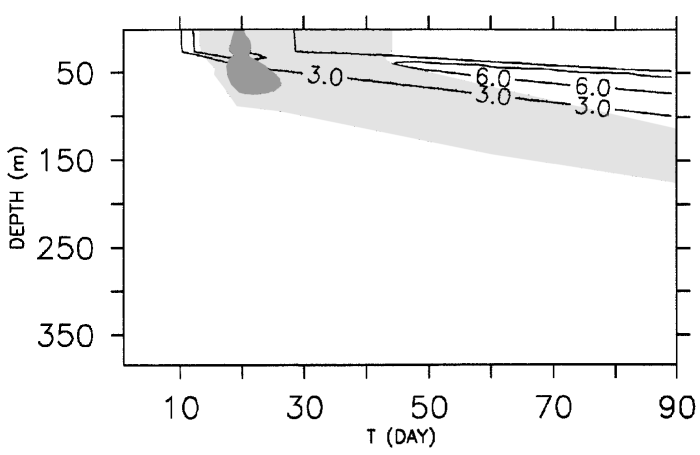

No Aggregation

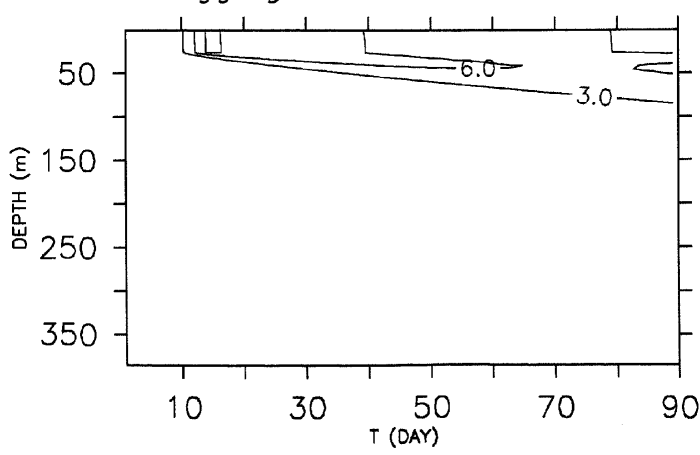

Sticky

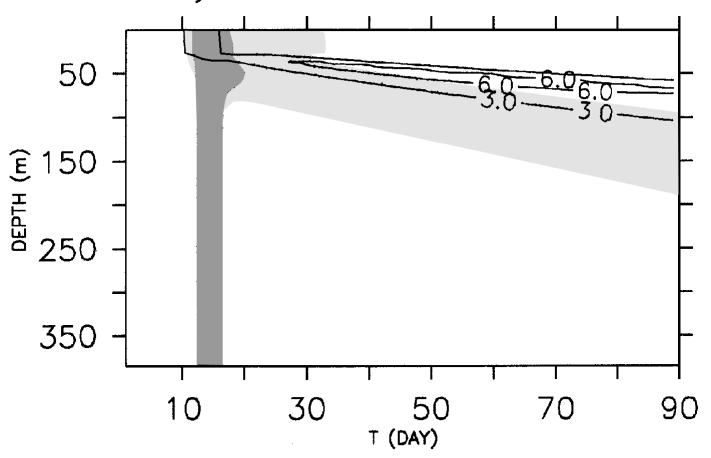

Sticky/low nitrate

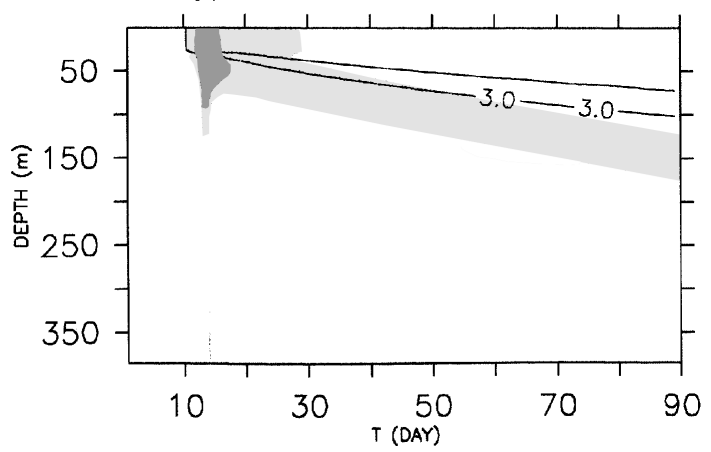

Figure 1. Phytoplankton mass (contour lines; contour interval is $3 \mathrm{mmol} \mathrm{N} \mathrm{m}^{-3}$ ) for the base model and three experiments over 90 days. The light grey area shows time and depth where the mass of aggregates sinking at least $10 \mathrm{~m} \mathrm{~d}^{-1}(>\approx 0.2 \mathrm{~mm}$ diameter $)$ exceeds $0.01 \mathrm{mmol} \mathrm{N} \mathrm{m}^{-3}$. The dark grey areas show time and depth where the mass of aggregates sinking at least $100 \mathrm{~m} \mathrm{~d}^{-1}(>\approx$ $1.5 \mathrm{~mm}$ diameter) exceeds $0.01 \mathrm{mmol} \mathrm{N} \mathrm{m}^{-3}$.
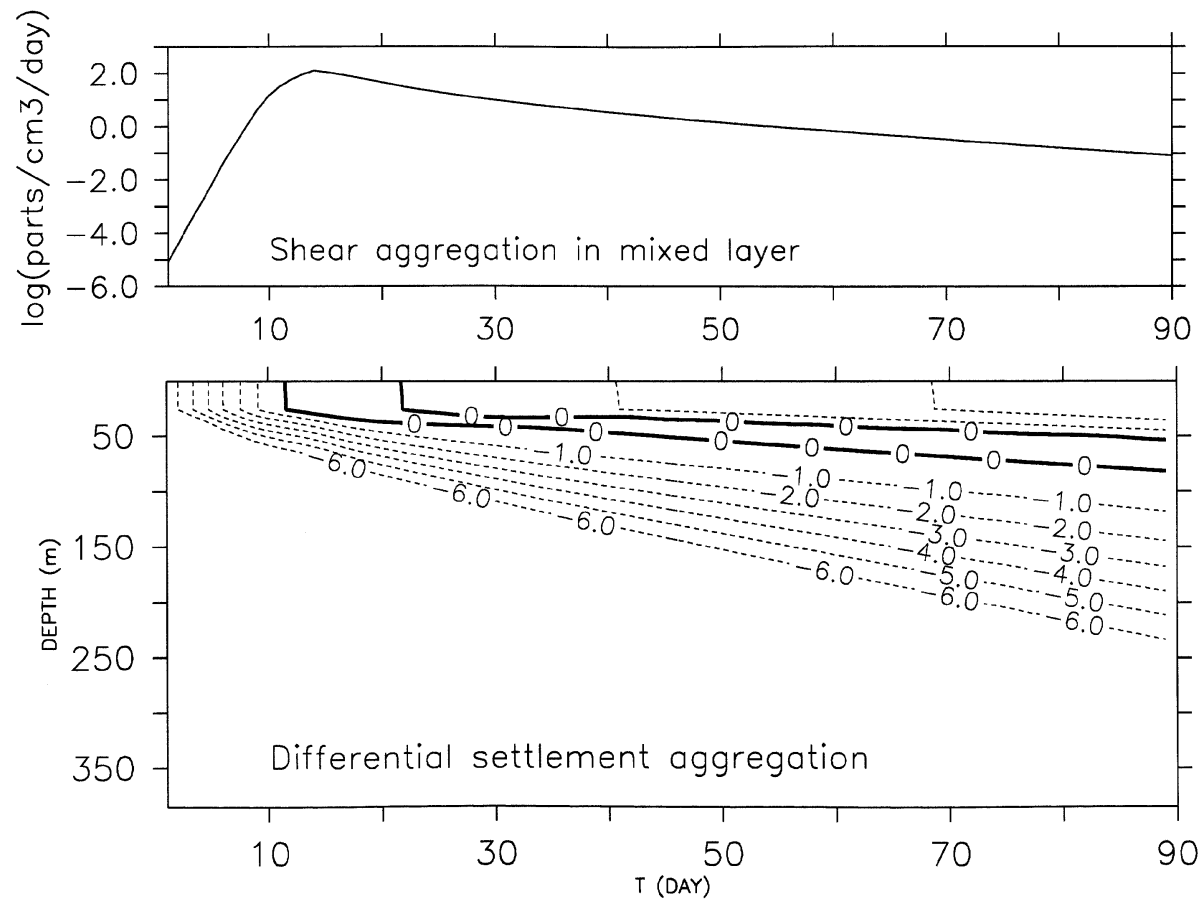

Figure 2. Aggregation (defined as number of collisions times particle stickiness) for collisions due to shear and differential settlement for the base model simulation. The logarithm of particles aggregating due to shear is shown for the mixed layer only in the upper panel over time. Aggregation due to differential settlement is shown over time and depth, with contour lines giving the logarithm of particles per $\mathrm{cm}^{3}$ and day. 
A five-fold increase in stickiness increases the aggregation rate, and has the effect of a higher and more rapid production of large aggregates (figure 1, upper right panel). Due to the higher production of large, fast settling aggregates, phytoplankton maximum concentrations are reduced (see table 2). If stickiness is increased, but the amount of total nitrate, that is available for phytoplankton growth is reduced (scenario "Sticky/Low nitrate") the production of large aggregates happens almost as fast, but to a lower extent (figure 1, lower right panel). Omitting aggregation at all (figure 1, lower left panel) increases the time phytoplankton stays in the mixed layer. As a consequence the light that is available for phytoplankton growth at greater depths (closer to the nitracline) is reduced, and the DCM is not as pronounced as in the simulations with aggregation. Aggregation thus promotes the formation of a DCM.

The timing and the amount of the formation of large aggregates directly affects the timing and the amount of sedimentation, as can be seen from figure 3 . In all simulations there is a maximum in sedimentation at $25 \mathrm{~m}$ (upper panel) a few days after the mixed layer bloom. The peak occurs very early in both of the
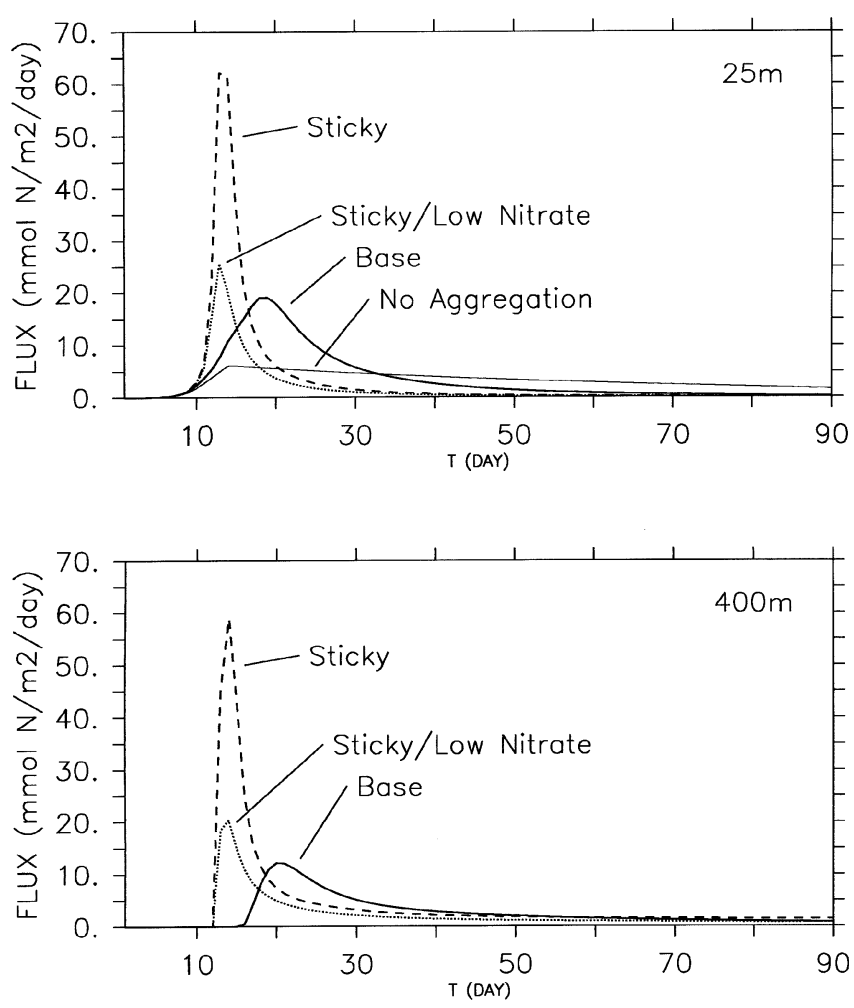

Figure 3. Sedimentation in $25 \mathrm{~m}$ (upper panel) and $400 \mathrm{~m}$ (lower panel) for the base run (bold lines) and the three experiments: scenario sticky (broken line), scenario sticky with low initial nitrate (dotted line) and the scenario without aggregation (thin straight line). For the last scenario, only sedimentation in $25 \mathrm{~m}$ is shown.
"Sticky" scenarios. The peak is less pronounced for the base run, where stickiness is only 0.1 , because aggregation occurs at a lower rate. Still the peak greatly exceeds that of the simulation without aggregation at all. Without aggregation, phytoplankton sinks at a low, constant sinking speed and sedimentation takes place over much longer time scales. Due to the very low settling speeds in this last scenario, of course there is no flux at $400 \mathrm{~m}$ in a simulation period of 90 days only (figure 3, lower panel). On the other hand, all of the scenarios including aggregation show a maximum in sedimentation within a few days after the maxima at $25 \mathrm{~m}$, and the maxima are almost as high as the shallow ones.

Table 2 shows the maximum phytoplankton concentration and the total primary production integrated over depth and time. Although aggregation as a density dependent process reduces the maximum concentrations that are achieved via the increase in sinking speed during bloom situations, it may enhance vertically integrated primary production. This increase in primary production is caused by the abovementioned promotion of a DCM: phytoplankton in the aggregation scenarios after the bloom move closer to the nitracline, where they still find sufficient light and nutrients for growth.

Aggregation enhances shallow (25 m) export, as can be seen from the difference in export between the base run and the run without aggregation (diagnostic tF25 in table 2). Shallow export is slightly reduced when simulating sticky aggregates, for the following reason: what sinks across $25 \mathrm{~m}$ is the initial nitrogen in these layers, plus the nitrate that is mixed up from below. Less nitrate is mixed in the 'Sticky' scenarios because below the mixed layer it is converted to phytoplankton, and sinks, sooner.

The enhancement of shallow sedimentation in the aggregation scenarios is greatest for short time scales, as can be seen from the percentage of mixed layer sedimentation in the first 20 days (eF25 in table 2). The percentage of phytoplankton that sinks out of the mixed layer is doubled when comparing the base scenario $(42 \%)$ with the simulation without aggregation $(20 \%)$. A five fold increase in stickiness produces again a doubling in the percentage of early export. If the stickiness is increased, but the possible density of phytoplankton is reduced by reducing initial nitrate, the effect of high stickiness on shallow export is less pronounced. This is due to the lower aggregation rate, when phytoplankton are less abundant.

Perhaps the most striking and interesting effects can be seen from the deep $(400 \mathrm{~m})$ sedimentation. As mentioned above, there is no deep sedimentation in the scenario without phytoplankton aggregation, because phytoplankton sink far too slowly. When simulating aggregation, the large aggregates sink to the deeper layers, which can be seen from the amount of sedimentation over the whole simulation period 
(186-366 mmol $\mathrm{N} \mathrm{m}^{-2}$ ), and they settle very quickly, as can be seen from the per cent of sedimentation that takes place during the first 20 days (16-59\%). Again, the effect of increasing stickiness on early sedimentation is more pronounced if at the same time the maximum phytoplankton concentration is high. If the stickiness is set to a value of 0.5 , another interesting feature arises: the deep sedimentation is higher than the shallow export (see table 2). This is due to the production in the DCM. Whereas with low stickiness aggregation below the mixed layer is low due to the absence of shear (see above), when increasing the stickiness the DCM may contribute to deep sedimentation, despite the fact that aggregation only takes place because of differential sedimentation.

\section{Simulations for the Arabian Sea}

The model has been set up and run for two locations in the Arabian Sea. The first location (hereafter called "S15", in accordance with the notation used by the US JGOFS process study) is an almost oligotrophic region, where phytoplankton is known to form a deep chlorophyll maximum almost throughout the year. Little sedimentation has been found on this site, with little variation throughout the year. The second location, hereafter named as "S04", has been chosen as an example for a region influenced strongly by monsoonal forcing, and exhibits a pronounced seasonal cycle of sedimentation with maxima of nitrogen and biogenic silica sedimentation (see figure 7).

\subsection{Model structure}

Mass balances. The nitrogen-based model described in the previous section has been extended by zooplankton (ZOO) and fecal pellets (DET) to provide the possibility to

- extract the contribution of phytoplankton sedimentation in comparison to the mass flux due to fecal pellets,

- investigate the sensitivity of model outcome (annual primary production, grazing and flux through sedimentation) to alterations in its setup.

Phytoplankton growth is again limited by the product of nutrient and light terms, as described in the previous section. In addition to the phytoplankton mass loss due to sedimentation, another linear term for phytoplankton mortality $\left(\lambda_{\mathrm{PHY}}\right)$ has been introduced into this model. Phytoplankton is assumed to be degraded to nitrate immediately after phytoplankton death, except for one (the detrital) scenario, where it is assumed not to dissolve, but is shifted into the detrital pool. The equation for nitrate (NO3) and phytoplankton mass (PHY) then read:

$$
\begin{aligned}
\frac{\partial \mathrm{NO} 3}{\partial t} & =-\frac{\mathrm{NO} 3}{k_{\mathrm{NO} 3}+\mathrm{NO} 3} J(z, t) \mathrm{PHY} \\
& +\left(\lambda_{\mathrm{ZOO}}+\kappa_{\mathrm{ZOO}} \mathrm{ZOO}\right) \mathrm{ZOO}+\lambda_{\mathrm{PHY}} \mathrm{PHY} \\
& +\lambda_{\mathrm{DET}} \mathrm{DET}+\frac{\partial}{\partial z} K(z) \frac{\partial \mathrm{NO} 3}{\partial z}, \\
\frac{\partial \mathrm{PHY}}{\partial t} & =\frac{\mathrm{NO} 3}{k_{\mathrm{NO} 3}+\mathrm{NO} 3} J(z, t) \mathrm{PHY}-\lambda_{\mathrm{PHY}} \mathrm{PHY} \\
& -G_{\mathrm{PHY}}-\frac{\partial \Psi}{\partial z}+\frac{\partial}{\partial z} K(z) \frac{\partial \mathrm{PHY}}{\partial z} .
\end{aligned}
$$

Phytoplankton is grazed by zooplankton $\left(G_{\mathrm{PHY}}\right)$. Zooplankton grazing follows a non-linear function (equation 12). A fraction $\left(1-\epsilon_{\mathrm{ZOO}}\right)$ of zooplankton grazing is lost due to sloppy feeding and fecal pellets. Zooplankton excrete dissolved inorganic nitrogen at a constant rate, $\lambda_{\text {zoo }}$. Mortality of zooplankton is simulated using a quadratic (density dependent) function $\left(\kappa_{\mathrm{ZOO}} \mathrm{ZOO}^{2}\right)$. Zooplankton are not able to maintain their vertical position by directed swimming, but are subject to vertical mixing like the other components.

$$
\begin{aligned}
\frac{\partial \mathrm{ZOO}}{\partial t}= & \epsilon_{\mathrm{ZOO}} G_{\mathrm{PHY}}-\left(\lambda_{\mathrm{ZOO}}+\kappa_{\mathrm{ZOO}} \mathrm{ZOO}\right) \mathrm{ZOO} \\
& +\frac{\partial}{\partial z} K(z) \frac{\partial \mathrm{ZOO}}{\partial z}
\end{aligned}
$$

with

$$
G_{\mathrm{PHY}}=\frac{\mu_{\mathrm{ZOO}} \mathrm{ZOOPHY}^{2}}{k_{p h y}^{2}+\mathrm{PHY}^{2}} .
$$

Detritus is produced by sloppy feeding and fecal pellet production of zooplankton, and is degraded by bacteria, which are not explicitely considered in this model $\left(\lambda_{\mathrm{DET}}\right)$. Detritus sinks at a constant settling velocity of $w_{\text {DET }}$.

$$
\begin{aligned}
\frac{\partial \mathrm{DET}}{\partial t}= & \left(1-\epsilon_{\mathrm{ZOO}}\right) G_{\mathrm{PHY}}-\lambda_{\mathrm{DET}} \mathrm{DET} \\
& -w_{\mathrm{DET}} \frac{\partial \mathrm{DET}}{\partial z}+\frac{\partial}{\partial z} K(z) \frac{\partial \mathrm{DET}}{\partial z} .
\end{aligned}
$$

Number balance. The implementation of aggregation and sinking has been described in the previous section. New aggregates are produced again at the same rate as the increase of phytoplankton mass due to assimilation of nitrate, so primary production has no effect on the size distribution of particles.

In a vertically resolved model there has to be a way aggregates disappear due to microbial breakdown especially at greater depths. This may happen by a variety of processes: Aggregates may breakup into smaller ones, without losing overall particulate mass, or they may become eroded at their outer edges, or even degrade to some dissolved constituent. Whereas the former processes would only affect the number of 
aggregates, but not their mass, the latter affects only their mass, but not their number. All processes decrease the average size of particles, i.e. they increase the slope of the size distribution, $\epsilon$. Little is known about the processes of erosion and degradation to dissolved organic or inorganic matter. Floc breakup mainly happens due to turbulent shear (Riebesell 1991; Ruiz and Izquierdo 1997), or when cells within colonies become senescent (Smayda and Boleyn 1965). The stability of the connection between the individual cells may vary with the material that interlocks the cells: e.g. Thalassiosira cells are joined into colonies by a gelatinous strand which may break apart more easily than the cells of the setose forms of Chaetoceros. For the sake of simplicity, neither of these processes is built into the current model, but as explained above particle degradation is assumed not to have any effect on the size distribution. This is done by reducing the mass and number by the same fraction $\lambda_{\mathrm{PHY}}$. For the sake of simplicity, it is also assumed that zooplankton feeding does not alter the size distribution of particles. The number of aggregates are reduced by the same proportion as their mass, and the equation for phytopankton numbers then reads:

$$
\begin{aligned}
& \frac{\partial \mathrm{PHYNOS}}{\partial t}=\frac{\mathrm{NO} 3}{k_{\mathrm{NO} 3}+\mathrm{NO} 3} J(z, t) \mathrm{PHYNOS} \\
& -\lambda \mathrm{PHYNOS}-\frac{\partial \Phi}{\partial z}-\xi-G_{\mathrm{PHY}} \frac{\mathrm{PHYNOS}}{\mathrm{PHY}} \\
& +\frac{\partial}{x} \partial z K(z) \frac{\partial \mathrm{PHYNOS}}{\partial z} .
\end{aligned}
$$

\subsection{Model setup, forcing and numerical grid}

Forcing and numerical grid. The model for the Arabian Sea consists of 50 numerical boxes, covering a water column of about $800 \mathrm{~m}$. The exponential grid of Haupt (1995) is again used to give extra resolution near the surface where light gradients are strongest.

Using prescribed values for the depth of the upper and lower thermocline (see below), the turbulent vertical eddy diffusion coefficient above the upper thermocline is set to a value of $k_{u p}=1000 \mathrm{~cm}^{2} \mathrm{~s}^{-1}$. Below the lower thermocline, turbulent diffusive mixing is set to a value of $k_{\text {low }}=1 \mathrm{~cm}^{2} \mathrm{~s}^{-1}$, which is about three times higher than the value given in Evans and Garçon (1997). Between both boundaries, the diffusion coefficient is interpolated using the cubic approximation presented by Evans and Garçon (1997). To allow for shear collisions below the mixed layer, the rate of turbulent shear below the mixed layer in this model has been set to $1 / 100$ of the mixed layer rate of turbulent shear $\left(0.84 \mathrm{~s}^{-1}\right)$.

The model is driven by daylength and daily integrated solar radiation, which has been computed according to Brock (1981) for the specific region $\left(10^{\circ}\right.$ and $17^{\circ} \mathrm{N}$ for $\mathrm{S} 15$ and S04, respectively). Light is reduced by cloudiness following Reed (1977), which has been interpolated from monthly means for the specific region as given by the EsbensenKushnir climatological data set (as available through ferret.wrc.noaa.gov/fbin/climate_server). Thermocline depth has been calculated from monthly mean temperature profiles as presented in the World Ocean Atlas (WOA, as available through ferret.wrc.noaa.gov/fbin/climate_server) using the criterion $\Delta \mathrm{T}=0.1^{\circ} \mathrm{C}$ and $\Delta \mathrm{T}=0.5^{\circ} \mathrm{C}$ for the location of the top and bottom thermocline, respectively. Mixed layer cycles for both stations according to this criterion, agree fairly well with the mixed layer depths calculated by Codispoti (unpubl.) for 1995 cruises for five days, using a criterion of a $.03 \mathrm{~kg} \mathrm{~m}^{-3}$ change in density (see also Kriest 1999).

Parameters. Most of the phytoplankton parameters are assigned the same values as in the previous section. Phytoplankton half saturation constant for NO3 uptake is set to $0.5 \mathrm{mmol} \mathrm{N} \mathrm{m}^{-3}$, a value which lies within the range presented by Eppley et al (1969), and is close to the value found by Fasham and Evans (1995). Zooplankton parameters also have been set to similar values as Fasham et al (1990) used in simulations with their model for Bermuda, and is close to what has been estimated for the northeastern North Atlantic (Fasham and Evans 1995). Quadratic zooplankton mortality has been set to a value of 0.05 , although Evans (1999) estimated it to be close to zero. Detrital sinking speed has been set to $10 \mathrm{~m} \mathrm{~d}^{-1}$. This is less than the sinking speed of large fecal pellets which may sink as fast as $100 \mathrm{~m} \mathrm{~d}^{-1}$ (Noji 1989); it represents a compromise among a variety of groups such as ciliates and copepods. The aggregation parameters have been set to the same values as given in the previous chapter.

The initial profiles for phytoplankton and nitrate have been taken from the profiles measured in January 1995 on the cruises of the American JGOFS process studies at the corresponding sites (as available through www1.whoi.edu/jgofs.html, June/August 1998).

Comparison with data. There exists a comprehensive data set, consisting of six vertical profiles for Chl $a$, primary production and other data measured during the US JGOFS process studies in 1995 for both locations (Chl $a$ and primary production by $\mathrm{R}$. Barber, as available through the US JGOFS data system www1.whoi.edu/jgofs.html June/August 1998, see also Morrison et al 1998). Together with the two profiles measured by the German JGOFS cruises in August 1995, altogether there are seven (eight) days for station S15 (S04) where model profiles can be compared with data. For the second region, additional data for vertical flux from sediment traps have been included in the model comparison with data 
(data by S. Honjo as available through the US JGOFS data system www1.whoi.edu/jgofs.html, see also Lee et al (1998).

\subsection{Simulations for station $S 15\left(10^{\circ} N 65^{\circ} \mathrm{E}\right)$}

The results for station S15 show the results for one year of simulation after a 100 year model spinup, i.e. the model has almost reached its equilibrium cycle. Nitrate concentration is uniform over the year, with a low $\left(<1 \mathrm{mmol} \mathrm{N} \mathrm{m}^{-3}\right)$ concentration in the upper layers (no figure). When the mixed layer deepens in summer (and, to a lesser extent, in winter), the nitracline also deepens and nitrate is entrained into the mixed layer and nitrate values become as high as $1 \mathrm{mmol} \mathrm{N} \mathrm{m}{ }^{-3}$. Phytoplankton rapidly assimilate these new nutrients. This leads to phytoplankton concentration increasing from $0.3 \mathrm{mmol} \mathrm{N} \mathrm{m} \mathrm{m}^{-3}$ during intermonsoon to more than $0.5 \mathrm{mmol} \mathrm{N} \mathrm{m}^{-3}$ during the Southwest Monsoon (figure 4).

Prior to this bloom, during the spring intermonsoon phase, a DCM is established, which vanishes when phytoplankton increases in the mixed layer in June/ July. Phytoplankton concentration and aggregation parameters are too low to allow the formation of large aggregates sinking faster than $100 \mathrm{md}^{-1}$, so their concentration for the whole year is below $0.001 \mathrm{mmol}$ $\mathrm{N} \mathrm{m}^{-3}$ (and not shown in figure 4). The concentration of phytoplankton is more or less constant throughout the year, and even less than zooplankton concentration, which varies between 0.2 and $0.7 \mathrm{mmol} \mathrm{N} \mathrm{m}^{-3}$ (shaded area in figure 5, mid panel). As there is little variation in phytoplankton concentration, sinking speed stays quite constant throughout the year, with low values in the upper layers $\left(<10 \mathrm{~m} \mathrm{~d}^{-1}\right)$ and little variation at a depth of $400 \mathrm{~m}$, where mass sinking speed only varies between 20 and $100 \mathrm{md}^{-1}$ (no figure). Similar to the other compartments, pellets too show little variation with depth and time, but mostly have relatively low values around $0-0.2 \mathrm{mmol} \mathrm{N} \mathrm{m}^{-3}$ (shaded area in figure 4, mid panel). There is therefore also little variation in deep $(800 \mathrm{~m})$ flux, which is plotted in figure 4, lower panel. The maximum of $0.2 \mathrm{mmol} \mathrm{N} \mathrm{m}^{-2} \mathrm{~d}^{-1}$ of sedimentation occurs after the mixed layer deepening in summer, and consists mainly of fecal pellets. A lower and less pronounced peak can be detected in spring, following the mixed layer deepening during that time. When integrating over one year and depth, primary production is about $210 \mathrm{~g} \mathrm{C} \mathrm{m}^{-2}$, of which $73 \%$ is grazed by zooplankton. Total sedimentation in $800 \mathrm{~m}$ is $32 \mathrm{mmol} \mathrm{N} \mathrm{m}^{-2}$, with little phytoplankton (18\%).

The comparison of model results for phytoplankton with chlorophyll data measured in 1995 has been done by converting model phytoplankton $\left(\mathrm{mmol} \mathrm{N} \mathrm{m}^{-3}\right)$ to Chl $a$ using a carbon to $\mathrm{Chl} a$ ratio of 80 (independent of depth), and a C:N ratio of 6.6. The results of the model simulations together with data measured on
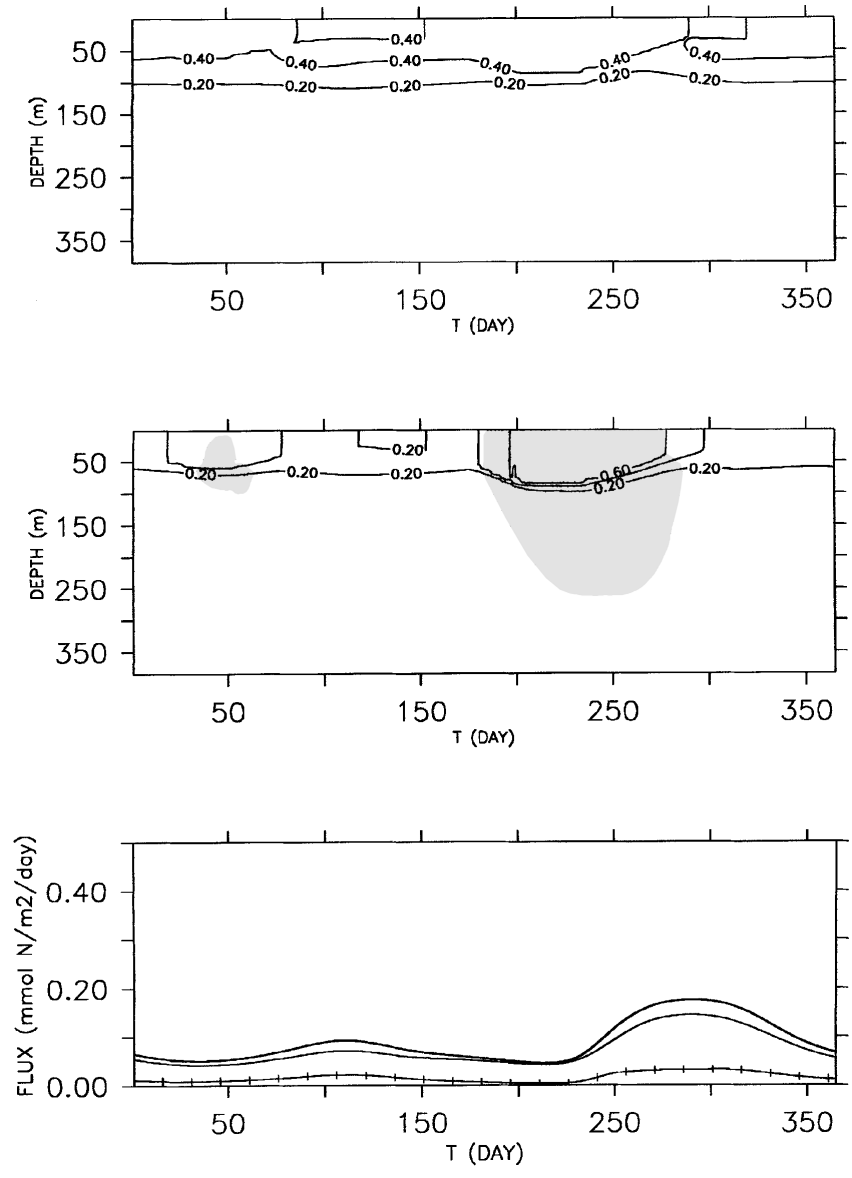

Figure 4. Upper panel: Phytoplankton mass for the model simulation at station S15 (upper $400 \mathrm{~m}$ ). Phytoplankton mass is shown by contour lines (contour intervals $0.2 \mathrm{mmol} \mathrm{N} \mathrm{m}^{-3}$ ). Mid panel: Zooplankton concentration (contour lines; contour intervals are $0.2 \mathrm{mmol} \mathrm{N} \mathrm{m}^{-3}$ ) for the model simulation at station S15 (upper $400 \mathrm{~m}$ ). The grey areas show the time and depth where fecal pellet concentration $\left(\operatorname{mmol~N~m}{ }^{-3}\right)$ exceeds $0.1 \mathrm{mmol} \mathrm{N} \mathrm{m}^{-3}$. Lower panel: Sedimentation in $800 \mathrm{~m}$ for the model simulation at station S15. Total flux in $800 \mathrm{~m}$ is denoted by a bold line. Fecal pellet flux is denoted by a thin line, while phytoplankton sedimentation is denoted by a thin line with bars. Units are $\mathrm{mmolN} \mathrm{m}^{-2} \mathrm{~d}^{-1}$.

the JGOFS cruises in 1995 on that station are plotted in figure 5. Chl $a$ in the upper $60 \mathrm{~m}$ is overestimated by the model for most times of the year. The model does not built a distinct DCM as shown by the data on the corresponding days, but instead its phytoplankton is distributed uniformly over the upper $70 \mathrm{~m}$, and then declines. As mentioned above, the formation of a DCM in nature may partly be caused by varying Chl:N ratios, as the phytoplankton adopts to low light conditions. This shade adaptation is not included in the model, but the formation of a DCM in the model might be more pronounced, if this was considered.

\subsection{Simulations for station S04 $\left(1^{m p} \mathrm{~N} 60^{\circ} \mathrm{E}\right)$}

Recent results of measurements carried out in the western Arabian Sea during the JGOFS Arabian Sea 

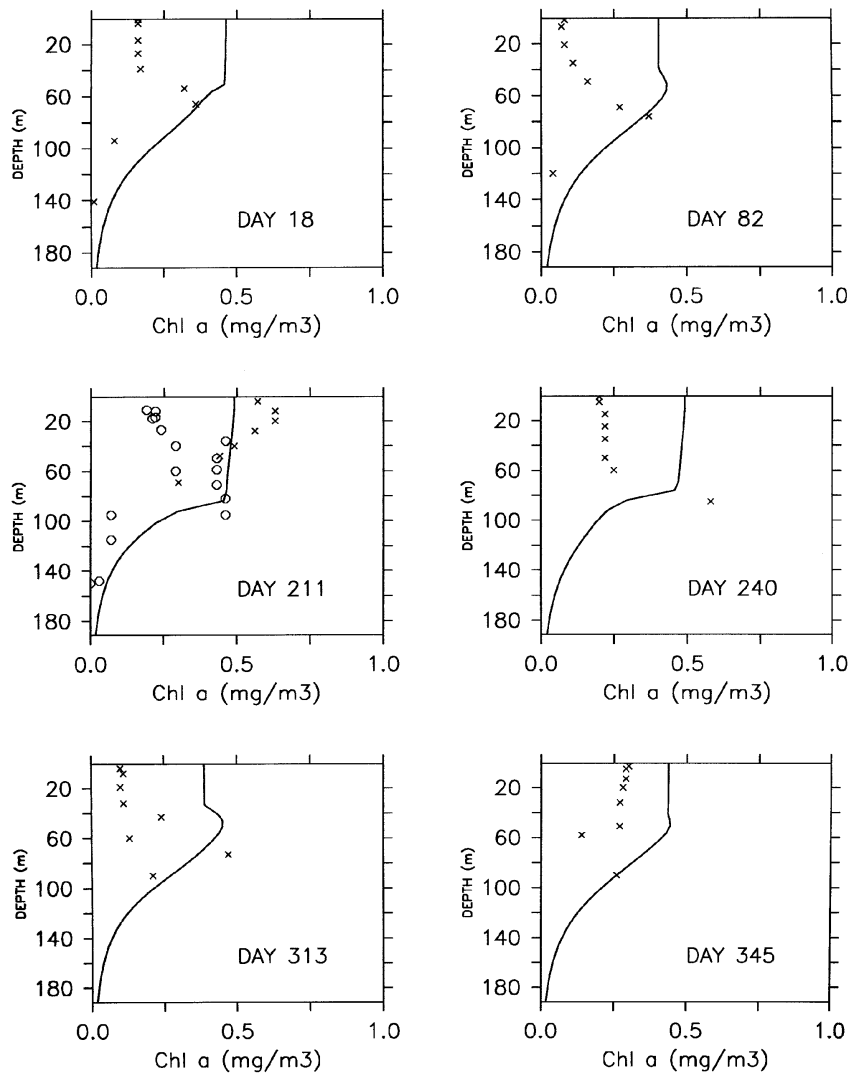

Figure 5. Vertical profiles for Chl $a$ for the base model simulation at station S15 (upper 200m), plus local measurements. Model profiles are displayed by a line for days 18, 82, 211, 240, 313 and 344. Measurements made on the US JGOFS cruises (data courtesy of R Barber) are displayed by crosses. Measurements made on METEOR M32/5 are denoted by open circles (day 205, shown in mid left panel). Unit is $\mathrm{mg} \mathrm{Chl} a \mathrm{~m}^{-3}$.

Process Study suggest that the high nutrient concentrations in August and September 1995 in the region around station S04 could be attributed to the influence of water masses formed by coastal upwelling which advected southeastwards (Banse 1987; Morrison et al 1998). This would lead to an increase in nutrient concentration, which cannot be accounted for in a 1-dimensional model, but would need to make use for example of the output of a 3-dimensional model of ocean circulation. This type of modeling is beyond the scope of this work. Instead, as a way of simulating the response of phytoplankton to the lateral input of nutrients during the Southwest Monsoon (SWM), for this site model simulations has been performed in which after a hundred year spinup of the base model simulation in the 101st year a nitrate intrusion on day 218 is simulated by assimilating the nitrate profile of the US JGOFS cruise TT050 for this particular station into the model by using the maximum of the interpolated empirical nitrate value and the model nitrate on this day.

This site is largely influenced by coastal upwelling, where large autotrophic cells, often diatoms, are known to dominate the phytoplankton community (Banse 1994; Krey 1973). The important contribution of diatoms to the phytoplankton community during the SWM at this site has been confirmed by HPLC analysis (Latasa and Bidigare, 1998, K. v. Bröckel, Institut für Meereskunde, Kiel, pers. comm.) as well as by microscopic analysis (Garrison et al 1998, v. Bröckel, pers. comm.). Because the stickiness of diatom aggregates may vary between 0.1 and 0.9 (Alldredge and McGillivary 1991; Dam and Drapeau 1995; Engel 1998), for this site three model simulations have been performed: one with low (0.1) stickiness, one with high (0.5) stickiness (scenario "Sticky"), and one without aggregation, where stickiness is set to 0 . In this last scenario ("Detritus" scenario), phytoplankton neither sinks nor aggregates. Instead, its constant mortality produces detritus, which, together with the fecal pellets produced by zooplankton, sinks at the constant sinking speed of $10 \mathrm{~m} \mathrm{~d}^{-1}$.

The results for phytoplankton, zooplankton and fecal pellet mass are rather similar for the different simulations (Kriest 1999), so only the results for the scenario with high (0.5) stickiness are shown in detail. The results for the sedimentation at $800 \mathrm{~m}$ for the three different runs will then be presented in the next section together with sediment trap data. When simulating a nitrate intrusion on day 218 by assimilating the nitrate profile measured on cruise TTN050, total nitrate input for the mixed layer for this day (depth of lower thermocline is $35 \mathrm{~m}$ ) equals $124 \mathrm{mmol} \mathrm{N}$, and $1794 \mathrm{mmol} \mathrm{N}$ for the whole water column. Following the nitrate intrusion on day 218, phytoplankton only reaches a maximum concentration of $1.7 \mathrm{mmol} \mathrm{N} \mathrm{m}{ }^{-3}$, but there are large aggregates (defined to be those that sink at least $100 \mathrm{md}^{-1}$ ) during the time of the bloom (dark grey area in figure 6 , upper panel). These aggregates rapidly sink out and have reached a depth of $800 \mathrm{~m}$ a few days after the nitrate intrusion.

Zooplankton reaches maximum concentration a few days after the bloom (about $1.8 \mathrm{mmol} \mathrm{N} \mathrm{m}^{-3}$ figure 6 , mid panel), and maximum pellet concentration is $0.5 \mathrm{mmol} \mathrm{N} \mathrm{m}^{-3}$. The occurrence of large aggregates is of course reflected in the sedimentation. Only a few days after the nitrate profile assimilation, sedimentation shows a distinct peak at $800 \mathrm{~m}$, which consists almost exclusively of phytoplankton (figure 6). Between days 270 and 350 the contributions of aggregates and fecal pellets to deep flux are comparable. The concentration of those aggregates that sink faster than fecal pellets is much less than the concentration of fecal pellets; but their sinking speed can be much greater.

When comparing model phytoplankton with the observed data for Chl $a$, model results and data match quite well on most days of the year, although the DCM on day 92 in the model simulation is not as pronounced as in the 1995 data (figure 7). 

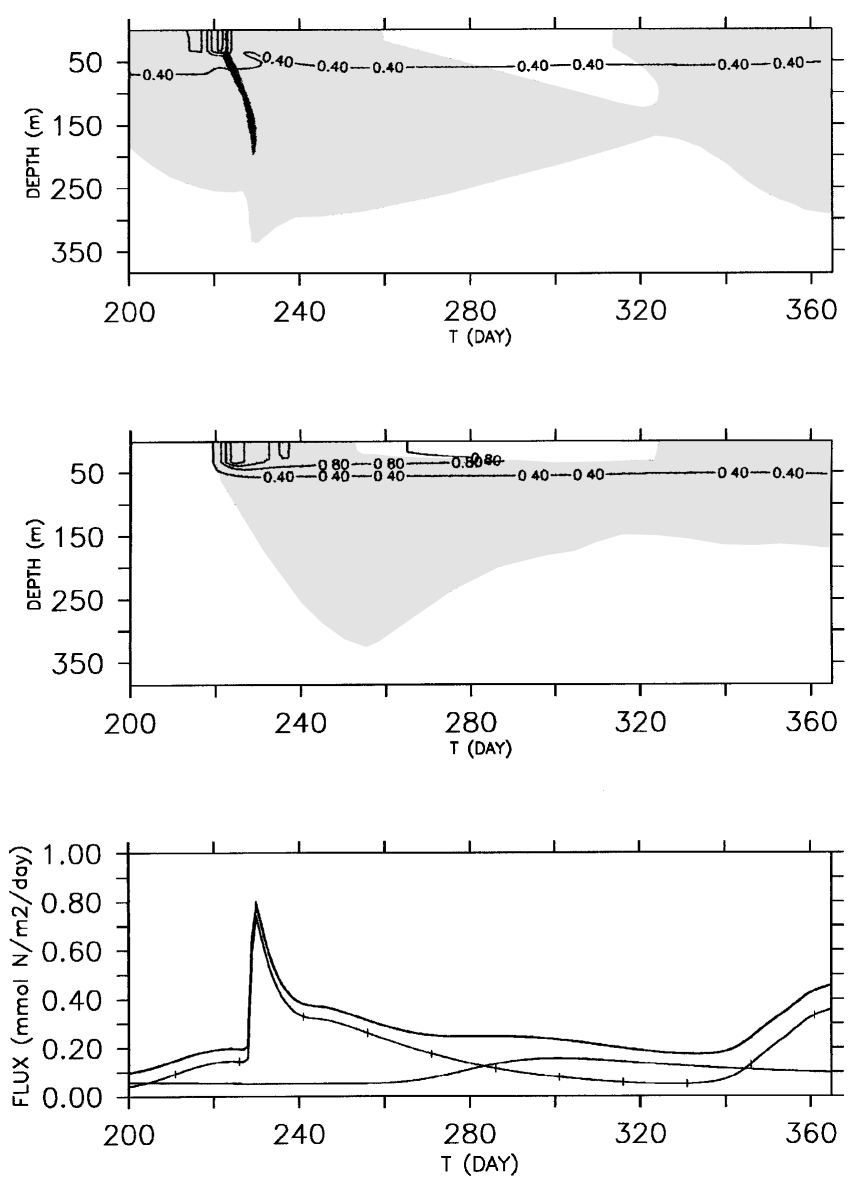

Figure 6. Upper panel: Phytoplankton mass for the "Sticky" scenario at station S04 with nitrate profile assimilation on day 218 (upper $400 \mathrm{~m}$, day 200-365). Phytoplankton mass is shown by contour lines (contour intervals $0.4 \mathrm{mmol} \mathrm{N} \mathrm{m}^{-3}$ ). The light grey area shows the time and depth where the mass of aggregates sinking at least $10 \mathrm{md}^{-1}$ (minimum diameter $\approx 0.2 \mathrm{~mm}$ ) exceeds $0.001 \mathrm{mmol} \mathrm{N} \mathrm{m}^{-3}$. The dark grey area shows the time and depth where the mass of aggregates sinking at least $100 \mathrm{~m} \mathrm{~d}^{-1}$ (minimum diameter $\approx 1.5 \mathrm{~mm}$ ) exceeds $0.001 \mathrm{mmol} \mathrm{N} \mathrm{m}^{-3}$. Mid panel: Zooplankton concentration (contour lines; contour intervals are $0.4 \mathrm{mmol} \mathrm{N} \mathrm{m}^{-3}$ ) for the "Sticky" scenario at station S04 with nitrate profile assimilation on day 218 (upper $400 \mathrm{~m}$, day 200-365). The shaded areas show the time and depth where fecal pellet concentration $\left(\mathrm{mmol} \mathrm{N} \mathrm{m}{ }^{-3}\right)$ exceeds $0.1 \mathrm{mmol} \mathrm{N} \mathrm{m}^{-3}$. Lower panel: Sedimentation in $800 \mathrm{~m}$ for the "Sticky" scenario at station S04 with nitrate profile assimilation on day 218. Total flux in $800 \mathrm{~m}$ is denoted by a bold line. Fecal pellet flux is denoted by a thin line, while phytoplankton sedimentation is denoted by a thin line with bars. Units are $\mathrm{mmol} \mathrm{N} \mathrm{m}^{-2} \mathrm{~d}^{-1}$.

\subsubsection{Model and observed sedimentation at station $\mathrm{SO}_{4}$}

The "Sticky" model in the previous section has been shown to reproduce a very distinct peak of sedimentation at a depth of $800 \mathrm{~m}$ immediately after the phytoplankton bloom. Trap data give mostly averages over a week or even a longer time period. This may have a tendency to flatten individual peaks. There is no way to re-examine the trap data with respect to the
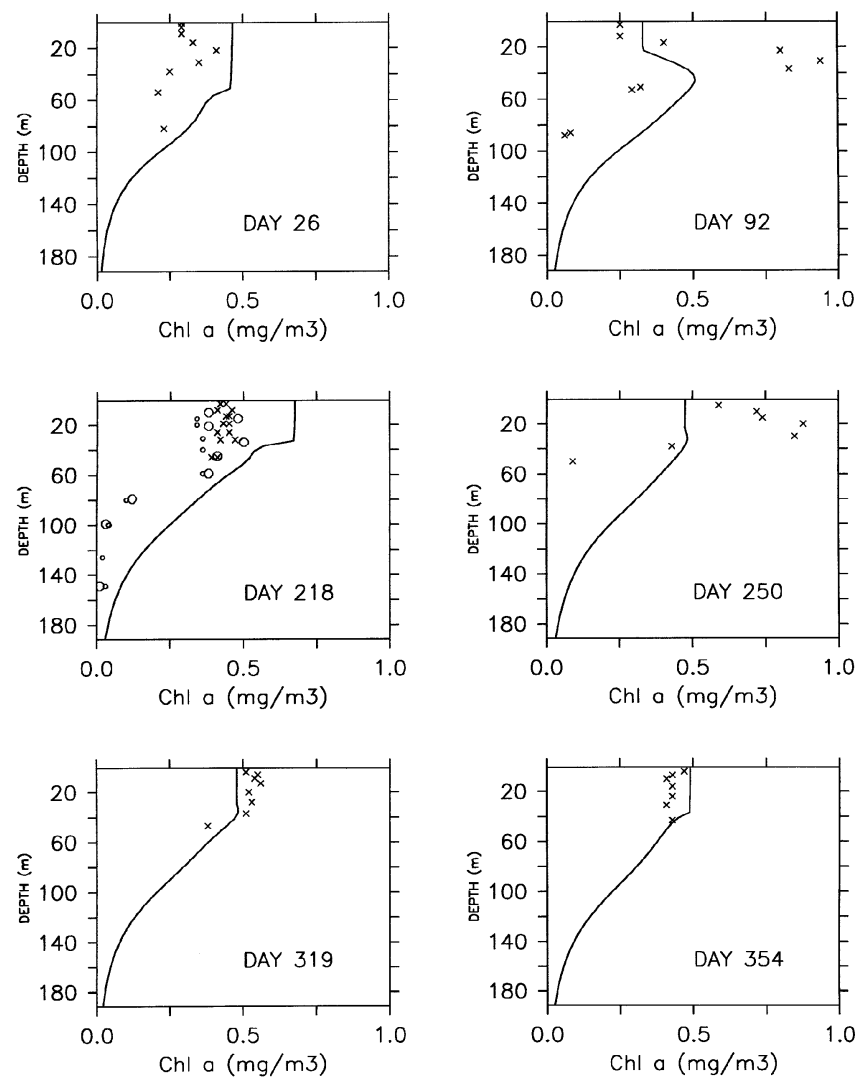

Figure 7. Vertical profiles for Chl $a$ for the model simulation at station S04 (upper $200 \mathrm{~m}$ ), plus local measurements. Model profiles are displayed by a line for days 26, 92, 218, 250, 319 and 354. Measurements made on the US JGOFS cruises (data courtesy of R Barber) are displayed by crosses. Measurements made on METEOR M32/5 on day 213 and 220 are denoted by small and large open circles, respectively. Unit is $\mathrm{mg} \mathrm{Chl} a \mathrm{~m}^{-3}$.

peaks that may have occurred during their opening interval, so the model flux for the three runs have been averaged over the same interval as the opening times of the trap J3 at the same location, at about $800 \mathrm{~m}$ depth during 1995 deployed, sampled and measured by S. Honjo (see above for data source). Figure 8 shows these averaged model fluxes for three model simulations (low stickiness A, "Sticky" scenario B, and "Detritus" scenario, C).

The model with low stickiness and the detritus scenario after averaging over the trap sampling intervals do not show any peaks of sedimentation, and their flux pattern does not coincide with the observed fluxes. Having a constant detrital sinking speed or low aggregation, most of the matter that is exported by sedimentation comes in the form of fecal pellets. The time lag between phytoplankton bloom and peak sedimentation is too large when compared with the observed flux. Only the model scenario with a stickiness of 0.5 shows a peak during summer monsoon, which mainly consists of phytoplankton. Summarizing, at this site a rather high stickiness is necessary to simulate the flux pattern that has been observed. 

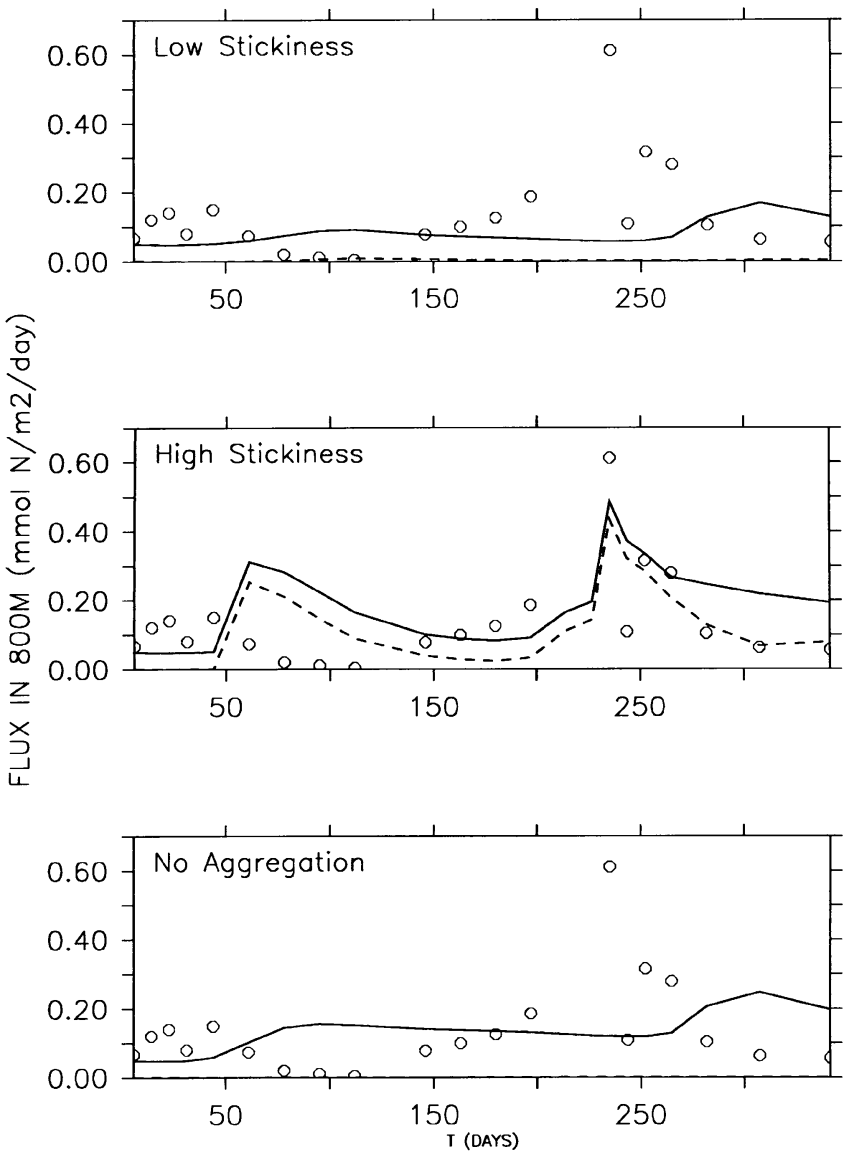

Figure 8. Phytoplankton (broken line) and total (straight line) sedimentation at $800 \mathrm{~m}$ for different model scenarios, together with local measurements of sedimentation on station S04 (circles; data courtesy of S Honjo). Upper panel: low (0.1) stickiness. Mid panel: "Sticky" scenario. Lower panel: "Detritus" scenario (no aggregation). Model results have been averaged over trap sampling intervals. Units are mmol $\mathrm{N} \mathrm{m}^{-2} \mathrm{~d}^{-1}$.

\section{Discussion}

The oligotrophic site in the central Arabian

Sea. There are other data sets we can compare with. The model for this site simulated low values $(<0.6 \mathrm{mg}$ Chl $a \mathrm{~m}^{-3}$ ) of phytoplankton with relatively little variation throughout the year. Low Chl $a$ concentra- tions (0.1-0.3 $\mathrm{mg} \mathrm{Chl} a \mathrm{~m}^{-3}$ ) with little variation over the year have also been measured on cruises carried out by the International Indian Ocean Expedition (IIOE) in the mid 60's (ATLANTIS cruises 8 and 15 in August/September 1963 and February/March 1965, respectively, Krey and Babenerd 1976). Primary productivity on this site during May/July 1964 was about $0.3 \mathrm{~g} \mathrm{C} \mathrm{m}^{-2} \mathrm{~d}^{-1}$, but also showed little variation throughout the year (Krey and Babenerd 1976).

Model annual primary production at this site was rather high in this model $\left(210 \mathrm{~g} \mathrm{C} \mathrm{m}^{-2} \mathrm{y}^{-1}\right.$, see table 3$)$. The value lies in the range of the annual primary production of 1995, when integrated over depth and year, which gives about $278 \mathrm{~g} \mathrm{C} \mathrm{m}^{-2} \mathrm{y}^{-1}$ (Lee et al 1998), but it is much higher than the estimated annual primary production of $25-73 \mathrm{~g} \mathrm{C} \mathrm{m}^{-2} \mathrm{y}^{-1}$ as presented by Krey (1973) for the open Indian Ocean.

This oligotrophic system showed little sedimentation. Pollehne et al (1993) using scanning electron microscopy found that a large amount of sedimentation in the central Arabian Sea in May could be attributed to copepod fecal pellets, which contained diatom and coccolithophorid shells. The autotrophic organisms grew mainly in the DCM at about $50 \mathrm{~m}$ depth (max. Chl $a$ about $1 \mathrm{mg} \mathrm{Chl} a \mathrm{~m}^{-3}$ ), whereas in the mixed layer a recycling system of small phytoplankton was found, so the DCM was the main source of sedimentation via fecal pellet sedimentation. This finding corresponds with the results of this work, where sedimentation happened mainly via fecal pellets. The model for the oligotrophic site exports $2.6 \mathrm{~g} \mathrm{C} \mathrm{m}^{-2} \mathrm{y}^{-1}$ at $800 \mathrm{~m}$, which agrees with the annual flux rates of $1.1-2.6 \mathrm{~g} \mathrm{C} \mathrm{m}^{-2-1}$ that have been found by Haake et al (1993) for the years of 1986-1988 on a station at $14.5^{\circ} \mathrm{N} 64.8^{\circ} \mathrm{E}$ at about $3000 \mathrm{~m}$ depth. A minimum estimate (which does not include all seasons) for 1995 of ca. $2.1 \mathrm{~g} \mathrm{C} \mathrm{m}^{-2} \mathrm{y}^{-1}$ is given by Lee et al (1998).

The results of the model simulations lie in the range of the data of the 1995 study; model primary production exceeds the production measured some decades ago. At $10^{\circ} \mathrm{N} 65^{\circ} \mathrm{E}$, phytoplankton growth is mainly controlled by the availability of nutrients that are mixed into the surface layers by mixed layer

Table 3. Maximum phytoplankton (max. PHY), Annual primary production (PP) (integrated over depth), grazing (integrated over depth, given as percent of primary production) and sedimentation $800 \mathrm{~m}$ for different simulations in the western and central Arabian Sea.

\begin{tabular}{|c|c|c|c|c|c|}
\hline $\begin{array}{l}\text { Location } \\
\text { Scenario }\end{array}$ & $\begin{array}{l}\max . \mathrm{PHY}^{-3} \\
\operatorname{mmol~} \mathrm{Nm}^{-3}\end{array}$ & $\begin{array}{c}\mathrm{PP} \\
\mathrm{g} \mathrm{C} \mathrm{m}^{-2}\end{array}$ & $\begin{array}{l}\text { Grazing } \\
\% \text { of PP }\end{array}$ & $\begin{array}{l}\text { Flux }(800 \mathrm{~m}) \\
\qquad \mathrm{g} \mathrm{C} \mathrm{m}^{-2}\end{array}$ & $\% \mathrm{PHY}$ \\
\hline $\begin{array}{l}\text { Central Arabian Sea } 10^{\circ} \mathrm{N} 65^{\circ} \mathrm{E} \\
\text { Low stickiness }\end{array}$ & 0.6 & 210 & 73 & 2.6 & 18 \\
\hline $\begin{array}{l}\text { Western Arabian Sea } 17^{\circ} \mathrm{N} 60^{\circ} \mathrm{E} \\
\text { Low stickiness } \\
\text { High stickiness } \\
\text { Detritus scenario }\end{array}$ & $\begin{array}{l}1.5 \\
1.7 \\
2.7\end{array}$ & $\begin{array}{l}252 \\
240 \\
190\end{array}$ & $\begin{array}{l}78 \\
75 \\
76\end{array}$ & $\begin{array}{l}2.5 \\
5.7 \\
4.1\end{array}$ & $\begin{array}{c}4 \\
61 \\
-\end{array}$ \\
\hline
\end{tabular}


deepening during both monsoon seasons. As phytoplankton never bloom with high concentrations, and stickiness has been set to a rather low value of 0.1 which simulates a low contribution of diatoms to the phytoplankton community, aggregation on this site is of minor importance to deep flux.

The site in the western Arabian Sea. The results of the International Indian Ocean Expedition (IIOE) showed a large spatial and temporal variability in Chl $a$ concentrations and primary production northwest of the Findlater Jet axis (Krey and Babenerd 1976). Generally, primary production and $\mathrm{Chl} a$ concentrations are higher in this area than in the central part of the Arabian Sea, with values around 0.3-0.5 mg Chl $a$ $\mathrm{m}^{-3}$ averaged over the period from May to October, and lower $\left(0.2 \mathrm{mg} \mathrm{Chl} a \mathrm{~m}^{-3}\right)$ during the rest of the year. The vertical pigment distribution was relatively uniform in August 1963 (ATLANTIS II, cruise 8, Krey and Babenerd 1976), with values around $0.5 \mathrm{mg}$ Chl $a \mathrm{~m}^{-3}$, which is very low when compared with CZCS data as for example, presented by Brock et al (1991) for the year 1979, giving values as high as $5.0 \mathrm{mg}$ Chl $a \mathrm{~m}^{-3}$ for regions near the Oman coast. The latter findings are higher than the model output, when simulating a nutrient intrusion in August.

This model only on one day simulates an intrusion of nitrate into the mixed layer, but it is likely that larger amounts of nutrients are advected from the coastal upwelling (Morrison et al 1998). A more detailed investigation and modelling of the lateral processes on this site is necessary to examine the goodness of fit of the model to the data. The relatively good match of the model to the 1995 data may be misleading - the station has only been visited on eight days in a year, with a low temporal resolution especially during times of high production. It may be possible that there were far higher phytoplankton concentrations between the days of observation. For example, at the beginning of a drift study carried out during the SWM 1997 the Chl $a$ concentration in the coastal upwelling were as high as $4 \mathrm{mg} \mathrm{Chl} a \mathrm{~m}^{-3}$, with a large amount of diatoms as indicated by biogenic silicate and Utermöhl countings. This bloom declined within a few days to values less than $1 \mathrm{mg}$ Chl $a \mathrm{~m}^{-3}$ (v. Brockel, pers. comm.). Given the high spatial and temporal variability for this region it would be interesting to compare the output of an eddyresolving three dimensional model of ocean circulation and biogeochemistry with satellite ocean colour data.

Vertically integrated primary production over the whole year according to the data presented by Krey and Babenerd is larger than $0.5 \mathrm{~g} \mathrm{C} \mathrm{m}^{-2} \mathrm{~d}^{-1}$ in this region, showing little variation throughout the year and giving a minimum annual integrated production of at least $160 \mathrm{~g} \mathrm{C} \mathrm{m}^{-2}$. Krey (1973) for the coastal upwelling gives a value of $124 \mathrm{~g} \mathrm{C} \mathrm{m}^{-2} \mathrm{y}^{-1}$. The model results are higher (190-252 $\left.\mathrm{g} \mathrm{C} \mathrm{m}^{-2}\right)$, but with
$2.3-2.6 \mathrm{~g} \mathrm{C} \mathrm{m}^{-2} \mathrm{~d}^{-1}$ reproduce the very high daily production rates that have been measured on various cruises in 1995 (Barber, unpubl., v. Bröckel, pers. comm.). Annual integrated production for 1995 is $413 \mathrm{~g} \mathrm{C} \mathrm{m}^{-2} \mathrm{y}^{-1}$ (Lee et al 1998). The model lies within the range of these data, especially when considering that the model is likely to underestimate the nitrate concentrations that occur during SWM at this site (see above).

Little is known about the grazing pressure of zooplankton, especially mesozooplankton, on phytoplankton in this region. It is unclear whether copepods prefer aggregates for their diet. Schnack (1983) in the northwest African upwelling found that the copepod Calanoides carinatus, which also commonly occurs in the Arabian Sea, does not graze on phytoplankton aggregates of the genus Thalassiosira parthenia. Other authors have found grazing of copepods on phytoplankton aggregates (Bochdansky and Herndl 1992; Lampitt et al 1993). The high mesozooplankton biomass that persists throughout the entire year in the Arabian Sea, and its ability to graze upon natural assemblages of diatoms e.g. off the Somali coast (Smith 1982) suggest that its grazing pressure on phytoplankton in general must be strong.

Sedimentation in the western Arabian Sea has been found to be strictly coupled to the monsoonal forcing, i.e. to a decrease in surface water temperature after onset of the SWM (Haake et al 1993). The increase in organic carbon flux was first accompanied by an increase of carbonate, and about one month later, by an increase in biogenic silica sedimentation at $3000 \mathrm{~m}$ depth. Between 22 and $42 \mathrm{mmol} \mathrm{N} \mathrm{m}^{-2} \mathrm{y}^{-1}$ sedimented in the years from 1986-1990. This is about as much as the model sedimentation at $800 \mathrm{~m}$ depth, which lies between 31 and $72 \mathrm{mmol} \mathrm{N} \mathrm{m}^{-2} \mathrm{y}^{-1}$ for the simulations with low and high aggregation, respectively. Converting the data by Lee et al. (1998) to mmol $\mathrm{N}$ by dividing them by 6.6 gives an annual sedimentation of $61 \mathrm{mmol} \mathrm{N} \mathrm{m}^{-2} \mathrm{y}^{-1}$. It should be noted, that at this site the flux collected by deeper traps (1500 and about $3000 \mathrm{~m}$ ) is of the same amount (Lee et al. 1998). Without setting the aggregation parameters to unrealistic high values (Engel 1998; Alldredge and McGillivary 1991), high aggregation produces the characteristic sedimentation signal at greater depths, which is often accompanied by high opal sedimentation, as well as it coincides with the annual integrated flux. Nevertheless, mesozooplankton as large organisms can produce large, rapidly settling pellets (Noji 1989; Fowler and Knauer 1986), with sinking velocities of tens to hundreds of meters per day, so another method of increasing model sedimentation could be to increase the pellet sinking speed in the model. This has not been done in this representation, because this would result in an increase in sedimentation even for the intermonsoon periods, which is not supported by the data. 
Implications for biogeochemical models. It has been mentioned before that a model with the climatological forcing fails to reproduce the annual cycle of nitrate and other compartments at station S04, as this region is likely to be influenced by lateral processes (Banse 1987; McCreary et al 1996; Young and Kindle 1994; Morrison et al 1998). A high importance of coastal upwelling and offshore advection for the patterns of the nitrogen compartments was also demonstrated by Keen et al (1997) when using a coupled NPZD model for the Arabian Sea. The simulation of nitrate supply in the model we presented should only serve as a first step towards representing the processes in this area.

Keen et al (1997) also performed experiments to investigate the response of the biological system of an initial surface population to an upwelling event. They found a high sensitivity of the model to alterations in the zooplankton grazing parameters. Nevertheless, it should be noted that their model only included a linear mortality term for phytoplankton to detritus, and no or a constant sinking speed of detritus itself. In a model of this type, due to the constant phytoplankton mortality, zooplankton is crucial to the control of phytoplankton standing stock. There is evidence, that a density dependent control is needed in models that simulates phytoplankton growth. For example, Fasham and Evans (1995) using nonlinear optimization techniques found a solution with a high chlorophyllspecific attenuation coefficient when fitting their model to the data of the northern North Atlantic. Hurtt and Armstrong (Hurtt and Armstrong 1996) in simulations for the Bermuda Time Series Station refer to aggregation when they assign a phytoplankton mortality depending on the square of the phytoplankton mass. Oschlies et al (2000) emphasize the role of a density dependent process such as aggregation to prevent phytoplankton concentrations from becoming too high in a coupled NPZD model for the North Atlantic. A formulation such as the phytoplankton aggregation presented here may serve as a tool not only to trigger aggregation and sedimentation, but also to keep phytoplankton standing stock at realistic concentrations, without altering the overall model response to physical forcing. As has been stated in the chapters before, the sinking speed of particles in the oceanic environment may vary over some orders of magnitudes (Smayda 1970; Noji 1989; Alldredge and Gotschalk 1988). The variation in sinking speed, and sinking flux, can be due to different species compositions in the water column, to their nutritional status (Waite and Thompson 1992; Waite et al 1992) or, as for example presented in this work, due to aggregation of phytoplankton.

This variation can be of importance for the organisms living on the ocean floor, because it determines the amount and quality of food that supplies benthic organisms. It also determines how much, and how fast carbon, that has been fixed in the upper layers of the ocean, is being transported to the ocean interior. This may be of some importance for the global carbon cycle: if, for example, carbon is incorporated into particles in the coastal upwelling along the Arabian coast with its narrow shelf, and these waters are transported offshore via eddies and filaments, where surface current velocities may be around $0.5 \mathrm{~m} \mathrm{~s}^{-1}$ (Keen et al 1997, Dengler, unpubl. data), the rate at which these carbon rich particles sink determines where they will be deposited. If the particles sink fast enough, they will be deposited on the shelf and their carbon becomes available for surface production very soon. On the other hand, slow sinking particles might be transported further offshore, if they don't degrade before they reach the deep sea floor. This type of process can be of importance to three dimensional models (Young and Kindle 1994; Keen et al 1997) that are concerned with sinking and deposition of organic matter. A more detailed analysis of the sinking speed in relation to the times scales of oceanic transport, or even the implementation of the aggregation equations presented here into a 3-dimensional model of ocean circulation and biogeochemistry is necessary to examine the effects of aggregation on carbon export to the ocean floor for this specific region.

\section{Conclusions}

It is possible to include a model for phytoplankton aggregation and variable sinking speed into a vertically resolved model of ocean biogeochemistry. The present simulations with constant physical forcing show the importance of phytoplankton aggregation for the amount and the timing of sedimentation in deeper layers. Simulations for the Arabian Sea demonstrate that, especially in the western part of this region which undergoes strong seasonal oscillations in physical forcing, aggregation may strongly influence the sedimentation pattern at $800 \mathrm{~m}$. Only when simulating sticky diatoms does the model reflect the annual cycle of $\mathrm{N}$-sedimentation that has been found at this site.

\section{Acknowledgements}

Iris Kriest is grateful to the scientists and crew members of the RV METEOR cruise M32/5 that helped to collect the data. The authors wish to express their sincere thanks to R Barber and S Honjo, who provided the Chl $a$ and sediment trap data collected during the US JGOFS process study. We thank two anonymous reviewers, whose comments helped to improve the manuscript. Funding for IK was provided by the German Federal Ministery for Research, contract No. 03 F0241 E. 


\section{A. Appendix}

\section{A.1 Sedimentation in the 1D-model}

Let

$$
F_{M}=\left(\frac{M}{m}\right)^{1-\epsilon(z)}
$$

be the fraction of particles being larger than the upper bound, $M$, and $w_{M}=B M^{\eta}$ the constant sinking speed of particles larger than $M, w_{m}=B m^{\eta}$ the sinking speed of a single cell and $w(\theta)=B \theta^{\eta}$ the size dependent sinking speed of a particle smaller than $M$. The equation for sedimentation of numbers of particles with $p(z, \theta)=A(z) \theta^{\epsilon(z)}$ being the number distribution at a certain depth is then

$$
\begin{aligned}
\Phi(z) & =\left[\int_{m}^{M} p(z, \theta) w(\theta) \mathrm{d} \theta+\int_{M}^{\infty} p(z, \theta) w_{M} \mathrm{~d} \theta\right] \\
& =\operatorname{PHYNOS}\left(\frac{(\epsilon(z)-1) w_{m}}{\epsilon(z)-\eta-1}-\frac{F_{M} \eta w_{M}}{\epsilon(z)-\eta-1}\right) .
\end{aligned}
$$

If the mass of a particle of size $\theta$ is described by $C \theta^{\zeta}$ and if the fraction of mass of particles larger than $\mathrm{M}$ is given by

$$
G_{M}=\left(\frac{M}{m}\right)^{1+\zeta-\epsilon(z)}
$$

then

$$
\begin{aligned}
\Psi(z) & =C\left[\int_{m}^{M} p(z, \theta) \theta^{\zeta} w(\theta) \mathrm{d} \theta+\int_{M}^{\infty} p(z, \theta) \theta^{\zeta} w_{M} \mathrm{~d} \theta\right] \\
& =\operatorname{PHY}\left(\frac{(\epsilon(z)-\zeta-1) w_{m}}{\epsilon(z)-\zeta-\eta-1}-\frac{G_{M} \eta w_{M}}{\epsilon(z)-\zeta-\eta-1}\right) .
\end{aligned}
$$

The expression in large brackets corresponds to the average mass sinking rate as presented for example in Fasham et al (1990), or to the $\bar{w}$ as described in KE99.

\section{A.2 Aggregation in the $1 D$-model}

For the evaluation of collisions due to shear, there are four double integrals to be solved:

$$
\begin{aligned}
I_{1}= & \int_{m}^{M} \int_{m}^{M} \beta_{\text {shear }}(\theta, \Theta) p(z, \theta) p(z, \Theta) \mathrm{d} \theta \mathrm{d} \Theta \\
= & 0.163 \text { shear PHYNOS }{ }^{2} \\
& \times 2\left[\left(F_{M}-1\right)\left(F_{M} M^{3}-m^{3}\right) \frac{\epsilon(z)-1}{\epsilon(z)-4}\right. \\
& +3\left(F_{M} M-m\right)\left(F_{M} M^{2}-m^{2}\right) \\
& \left.\times \frac{(\epsilon(z)-1)(\epsilon(z)-1)}{(\epsilon(z)-2)(\epsilon(z)-3)}\right], \\
I_{2}= & \int_{m}^{\infty} \int_{m}^{M} \beta_{\text {shear }}(\theta, \Theta) p(z, \theta) p(z, \Theta) \mathrm{d} \theta \mathrm{d} \Theta \\
= & 0.163 \text { shear } \operatorname{PHYNOS}^{2}
\end{aligned}
$$

$$
\begin{aligned}
& \times F_{M}\left[\left(M^{3}+3\left(M^{2} m \frac{\epsilon(z)-1}{\epsilon(z)-2}\right.\right.\right. \\
& \left.\left.+M m^{2} \frac{\epsilon(z)-1}{\epsilon(z)-3}\right)+m^{3} \frac{\epsilon(z)-1}{\epsilon(z)-4}\right),
\end{aligned}
$$

$$
\begin{aligned}
& \left.-F_{M} M^{3}\left(1+3\left(\frac{\epsilon(z)-1}{\epsilon(z)-2}+\frac{\epsilon(z)-1}{\epsilon(z)-3}\right)+\frac{\epsilon(z)-1}{\epsilon(z)-4}\right)\right] \\
I_{3} & =\int_{m}^{M} \int_{M}^{\infty} \beta_{\text {shear }}(\theta, \Theta) p(z, \theta) p(z, \Theta) \mathrm{d} \theta \mathrm{d} \Theta=I_{2}, \\
I_{4} & =\int_{M}^{\infty} \int_{M}^{\infty} \beta_{\text {shear }}(\theta, \Theta) p(z, \theta) p(z, \Theta) \mathrm{d} \theta \mathrm{d} \Theta \\
& =0.163 \text { shear PHYNOS } F_{M} F_{M} 8 M^{3} .
\end{aligned}
$$

The number of particles colliding due to shear forces, $\xi_{\text {shear }}$ is then given by the sum of these four integrals:

$$
\xi_{\text {shear }}(z)=I_{1}+I_{2}+I_{3}+I_{4}=I_{1}+2 I_{2}+I 4 \text {. }
$$

Because particles larger than size $M$ thereafter sink at a constant speed, the evaluation for the number of collisions due to differential settlement can be presented as follows, with $S_{M}$ giving the relationship between the sinking rate of large particles to the sinking rate of one single cell:

$$
\begin{aligned}
S_{M}= & \left(\frac{M}{m}\right)^{\eta}, \\
I_{1}= & 2 \int_{m}^{M} \int_{m}^{\Theta} \beta_{\text {sett }}(\theta, \Theta) p(z, \theta) p(z, \Theta) \mathrm{d} \theta \mathrm{d} \Theta \\
= & 2 \pi 0.125 P H Y N O S^{2}(\epsilon(z)-1)^{2} w_{m} \\
& \times\left[m ^ { 2 } \left(\frac{1-F_{M} S_{M}}{(\epsilon(z)-3)(\epsilon(z)-\eta-1)}\right.\right. \\
& \left.-\frac{1-F_{M}}{(\epsilon(z)-\eta-3)(\epsilon(z)-1)}\right) \\
& \left.-\frac{\left(F_{M} F_{M} M^{2} S_{M}-m^{2}\right) \eta}{(\epsilon(z)-\eta-3)(\epsilon(z)-3)(2 \epsilon(z)-\eta-4)}\right] \\
I_{2}= & \int_{M}^{\infty} \int_{m}^{M} \beta_{\text {sett }}(\theta, \Theta) p(z, \theta) p(z, \Theta) \mathrm{d} \theta \mathrm{d} \Theta \\
= & \pi 0.125(\epsilon(z)-1) P H Y N O S^{2} F_{M} w_{m} \\
& \times\left[S_{M} \frac{m^{2}-F_{M} M^{2}}{\epsilon(z)-3}-\frac{m^{2}-F_{M} M^{2} S_{M}}{\epsilon(z)-\eta-3}\right], \\
I_{3}= & \int_{m}^{M} \int_{M}^{\infty} \beta_{\text {sett }}(\theta, \Theta) p(z, \theta) p(z, \Theta) \mathrm{d} \theta \mathrm{d} \Theta=I_{2}, \\
I_{4}= & \int_{M}^{\infty} \int_{M}^{\infty} \beta_{\text {sett }}(\theta, \Theta) p(z, \theta) p(z, \Theta) \mathrm{d} \theta \mathrm{d} \Theta=0 .
\end{aligned}
$$

The number of particles colliding due to shear forces, $\xi_{\text {sett }}$ is then given by the sum of these four integrals:

$$
\xi_{\text {sett }}(z)=I_{1}+I_{2}+I_{3}+I_{4}=I_{1}+2 I_{2} .
$$

Then the sum of equations (15) and (17) times stickiness give the loss of particles due to aggregation:

$$
\xi(z)=0.5 \operatorname{stick}\left(\xi_{\text {shear }}(z)+\xi_{\text {sett }}(z)\right) .
$$




\section{References}

Alldredge A L and Gotschalk C 1988 In situ settling behaviour of marine snow; Limnol. Oceanogr. 33(3) 339-351

Alldredge A L and Gotschalk C 1989 Direct observations of the mass flocculation of diatom blooms: characteristics, settling velocities and formation of diatom aggregates; Deep-Sea Res. 36(2) 159-171

Alldredge A L and McGillivary P 1991 The attachment probabilities of marine snow and their implications for particle coagulation in the ocean; Deep-Sea Res. 38(4) 431-443

Alldredge A L and Silver M W 1988 Characteristics, dynamics and significance of marine snow. Progress in Oceanography 20(41-82)

Banse K 1987 Seasonality of phytoplankton chlorophyll in the central and northern Arabian Sea. Deep-Sea Res. 34 713-723

Banse K 1994 On the coupling of hydrography, phytoplankton, zooplankton, and settling organic particles offshore in the Arabian Sea; Proc. Indian Acad. Sci. (Earth Planet. Sci.) $\mathbf{1 0 3}(2)$ 125-161

Bochdansky A B and Herndl G H 1992 Ecology of amorphous aggregations (marine snow) in the Northern Adriatic Sea. III. Zooplankton interactions with marine snow; Mar. Ecol. Progr. Ser. 87 135-146

Brock J C, McClain C R, Luther M E and Hay W W 1991 The phytoplankton bloom in the northwestern Arabian Sea during the southwest monsoon of 1979; J. Geophys. Res. 96(C11) 20623-20642

Brock T D 1981 Calculating solar radiation for ecological studies; Ecol. Model. 14 1-19

Brown P N, Byrne G D and Hindmarsh A C 1989 VODE: A Variable Coefficient ODE Solver; SIAM J. Sci. Stat. Comput. 10 1038-1051

Dam H G and Drapeau D T 1995 Coagulation efficiency, organic-matter glues and the dynamics of particles during a phytoplankton bloom in a mesocosm study; Deep-Sea Res. II 42(1) 111-123

Engel A 1998 Bildung, Zusammensetzung und Sinkgeschwindigkeiten mariner Aggregate. Ber. Institut fur Meereskunde, Kiel 300. Christian-Albrechts-Universitat zu Kiel, 145 pp.

Eppley R W, Rogers J N and McCarthy J J 1969 Halfsaturation constants for uptake of nitrate and ammonium by marine phytoplankton; Limnol. Oceanogr. 14 912-920

Evans G T 1999 The role of local models and data sets in the Joint Global Ocean Flux Study; Deep-Sea Res. I 46 1369-1389

Evans G T and Garçon V 1997 One-dimensional models of water column biogeochemistry; JGOFS Report 23. Scientific Committee on Oceanic Research, Bergen, Norway, 85 pp.

Evans G T and Parslow J S 1985 A model of annual plankton cycles; Biol. Oceanogr. 3 327-347

Fasham M J R and Evans G T 1995 The use of optimization techniques to model marine ecosystem dynamics at the JGOFS Station at $47^{\circ} \mathrm{N}, 20^{\circ} \mathrm{W}$; Phil. Trans. Roy. Soc. London B 348 203-209

Fasham M J R, Ducklow H W and McKelvie S M 1990 A nitrogen-based model of plankton dynamics for the oceanic mixed layer; J. Mar. Res. 48 591-639

Fowler S W and Knauer G A 1986 Role of large particles in the transport of elements and organic compounds through the oceanic water column; Prog. Oceanog. 16 147-194

Garrison D L, Gowing M M and Hughes M P 1998 Nano- and microplankton in the northern Arabian Sea during the Southwest Monsoon, August-September 1995: A US-JGOFS study; Deep-Sea Res. II 45(10-11) 2269-2299

Haake B, Ittekkot V, Rixen T, Ramaswamy V, Nair R R and Curry W B 1993 Seasonality and interannual variability of particle fluxes to the deep Arabian Sea; Deep-Sea Res. 40(7) 1323-1344
Haupt O J 1995 Modellstudien zum pelagischen Stickstoffumsatz und vertikalen Partikelflu $\beta$, in der Norwegensee; Berichte aus dem Sonderforschungsbereich 313 60. Christian-AlbrechtsUniversitat zu Kiel, 140 pp.

Hurtt G C and Armstrong R A 1996 A pelagic ecosystem model calibrated with BATS data; Deep-Sea Res. II 43(2/3) 653-683

Jackson G A 1990 A model for the formation of marine algal flocs by physical coagulation processes; Deep-Sea Res. 37(8) 1197-1211

Keen T R, Kindle J C and Young D K 1997 The interaction of Southwest Monsoon upwelling, advection and primary production in the northwest Arabian Sea; J. Mar. Systems 13(1-4) 61-82

Krey J 1973 Primary Production of the Indian Ocean. Chap. 2.1, pages 155-126 In: The Biology of the Indian Ocean (ed) B Zeitzschel (Berlin: Springer)

Krey J and Babenerd B 1976 Phytoplankton production. Atlas of the International Indian Ocean Expedition; Institut fur Meereskunde an der Christian-Albrechts-Universiẗat Kiel, 70 pp.

Kriest I 1999 The influence of phytoplankton aggregation on sedimentation - A model study; Ber. Institut fur Meereskunde 306. Christian-Albrechts-Universiẗat zu Kiel, 136 pp.

Kriest I and Evans G T 1999 Representing phytoplankton aggregates in biogeochemical models; Deep-Sea Res. I 46 $1841-1859$

Lampitt R S 1985 Evidence for the seasonal deposition of detritus to the deep-sea floor and its subsequent resuspension; Deep-Sea Res. 32(8) 885-897

Lampitt R S, Hillier W R and Challenor P G 1993 Seasonal and diel variation in the open ocean concentration of marine snow aggregates; Nature 362 737-739

Latasa M and Bidigare R R 1998 A comparison of phytoplankton populations of the Arabian Sea during the spring intermonsoon and southwest monsoon of 1995 as described by HPLC-analyzed pigments; Deep-Sea Res. II 45(10-11) 2133-2170

Lee C, Murray D W, Barber R T, Buesseler K O, Dymond J, Hedges J I, Honjo S, Manganini S J, Marra J, Moser C, Peterson M L, Prell W L and Wakeham S G 1998 Particulate organic carbon fluxes: compilation of results from the 1995 US JGOFS Arabian Sea Process Study by the Arabian Sea Process Study; Deep-Sea Res. II 45(10-11) 2489-2501

McCreary J P, Kohler K E, Hood R R and Olson D B 1996 A four-component ecosystem model of biological activity in the Arabian Sea; Prog. Oceanog. 37 193-240

Morrison J, Codispoti L A, Gaurin S, Jones B, Manghnani V and Zheng Z 1998 Seasonal variation of hydrographic and nutrient fields during the US JGOFS Arabian Sea Process Study; Deep-Sea Res. II 45(10-11) 2053-2101

Nair R R, Ittekkot V, Manganini S J, Ramaswamy V, Haake B, Degens E T, Desai B N and Honjo S 1989 Increased particle flux to the deep ocean related to monsoons Nature 338 $749-751$

Noji T 1989 The influence of zooplankton on sedimentation in the Norwegian Sea; Ber. Sonderforschungsbereich 313 17. Christian-Albrechts-Universiẗat zu Kiel, $183 \mathrm{pp}$.

Oschlies A, Koeve W and Garçon V 2000 An eddy-permitting coupled physical-biological model for the North Atlantic. 2. Ecosystem dynamics and comparison with satellite and JGOFS local studies data; Global Biogeochemical Cycles. 14 (1) 499-523

Pollehne F, Klein B and Zeitzschel B 1993 Low light production and export production in the deep chlorophyll maximum layer in the northern Indian Ocean; Deep-Sea Res. II 40(3) 737-752

Reed R K 1976 On estimating insolation over the ocean; Journal of Physical Oceanography 7 482-485 
Riebesell U 1991 Particle aggregation during a diatom bloom. I. Physical aspects; Mar. Ecol. Progr. Ser. 69 273-280

Riebesell U and Wolf-Gladrow D 1992 The relationship between physical aggregation of phytoplankton and particle flux: a numerial model; Deep-Sea Res. 39(7/8) 1085-1102

Ruiz J and Izquierdo A 1997 A simple model for the break-up of marine aggregates by turbulent shear; Oceanologica Acta 20(4) 597-605

Schnack S 1983 On the feeding of copepods on Thalassiosira parthenia from the Northwest African upwelling area; Mar. Ecol. Progr. Ser. 11 49-53

Smayda T J 1970 The suspension and sinking of phytoplankton in the sea; Mar. Biol. Ann. Rev. 8 353-414

Smayda T J and Boleyn B J 1965 Experimental observations on the flotation of marine diatoms. II. Skeletonema costatum and Rhizosolenia setigera; Limnol. Oceanogr. 11 18-34
Smith S L 1982 The northwestern Indian Ocean during the monsoons of 1979: distribution, abundance, and feeding of zooplankton; Deep-Sea Res. 29(11A) 1331-1353

Smith Jr K L, Baldwin R J, Glatts R C, Kaufmann R S and Fisher E C 1998 Detrital aggregates on the sea floor: Chemical composition and aerobic decomposition rates at a time-series station in the abyssal NE Pacific; Deep-Sea Res. II 45 843-880

Waite A, Bienfang P K and Harrison P J 1992 Spring bloom sedimentation in a subarctic ecosystem. I. Nutrient sensitivity. Mar. Biol. 114

Waite A M and Thompson P A 1992 Does energy control the sinking rates of marine diatoms? Limnol. Oceanogr. 37(3) 468-477

Young D K and Kindle J C 1994 Physical processes affecting the availability of dissolved silicate for diatom production in the Arabian Sea; J. Geophys. Res. 99(C11) 22619-22632 